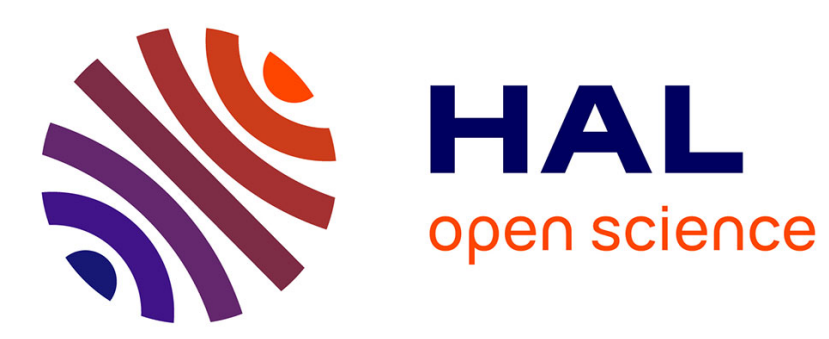

\title{
Education, Life Expectancy and Family Bargaining: The Ben-Porath Effect Revisited
}

Laura Leker, Grégory Ponthière

\section{To cite this version:}

Laura Leker, Grégory Ponthière. Education, Life Expectancy and Family Bargaining: The Ben-Porath Effect Revisited. 2012. halshs-00715104

\section{HAL Id: halshs-00715104 https://shs.hal.science/halshs-00715104}

Preprint submitted on 6 Jul 2012

HAL is a multi-disciplinary open access archive for the deposit and dissemination of scientific research documents, whether they are published or not. The documents may come from teaching and research institutions in France or abroad, or from public or private research centers.
L'archive ouverte pluridisciplinaire HAL, est destinée au dépôt et à la diffusion de documents scientifiques de niveau recherche, publiés ou non, émanant des établissements d'enseignement et de recherche français ou étrangers, des laboratoires publics ou privés. 


\title{
PARISSCHOQL OF ECONOMICS
}

WORKING PAPER N²012 - 32

Education, Life Expectancy and Family Bargaining: The BenPorath Effect Revisited

\author{
Laura Leker \\ Grégory Ponthière
}

JEL Codes: D13, J10, 041

Keywords: Education ; Life Expectancy ; Family Bargaining ; OLG Model

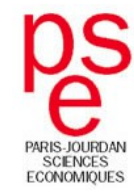




\title{
Education, Life Expectancy and Family Bargaining: The Ben-Porath Effect Revisited*
}

\author{
Laura Leker ${ }^{\dagger} \quad$ Gregory Ponthiere ${ }^{\ddagger}$
}

June 21, 2012

\begin{abstract}
Following Ben-Porath (1967), the influence of life expectancy on education has attracted much attention. Whereas existing growth models rely on an education decision made either by the child or by his parent, we revisit the Ben-Porath effect when the education is the outcome of a bargaining between the parent and the child. We develop a three-period OLG model with human capital accumulation and endogenous life expectancy, and show that, as a result of the unequal life horizons faced by parents and children, the Ben-Porath effect depends on the distribution of bargaining power within the family, which in turn affects the long-run dynamics of the economy. Using data on 17 OECD countries (1940-1980), we show that the introduction of intergenerational bargaining on education helps to rationalize the observed education patterns across countries.

Keywords: education, life expectancy, family bargaining, OLG model. JEL codes: D13, J10, O41.
\end{abstract}

*The authors are grateful to Daniel Cohen, Marion Davin and Volker Meier for their comments on this paper.

${ }^{\dagger}$ Paris School of Economics. Ecole Normale Supérieure, 48 bd Jourdan, 75014 Paris, France. E-mail: leker@pse.ens.fr

${ }^{\ddagger}$ Ecole Normale Superieure, Paris School of Economics. Ecole Normale Supérieure, 48 bd Jourdan, 75014 Paris, France. E-mail: gregory.ponthiere@ens.fr 


\section{Introduction}

Following the pioneer works by Lucas (1988) and Romer (1990), human capital accumulation is now regarded as a major factor of growth. As it is widely acknowledged, the human capital accumulation process is strongly related to demographic trends, concerning both mortality and fertility (Ehrlich and Lui 1991, Boucekkine et al 2002). On the mortality side, a major link was emphasized by Ben Porath (1967). The so-called Ben Porath effect states that, when life expectancy increases, lifetime returns on education investment tend, under general conditions, to increase, leading to a rise in the optimal education.

In accordance with the Ben-Porath hypothesis, we observe, for most countries, a positive correlation between life expectancy and education. To illustrate this, Figure 1 presents period life expectancies at birth and average years of education per cohort from Cohen and Leker (2012) for 5 countries over 1940-1980. The correlation between the two variables is positive for all countries. ${ }^{1}$

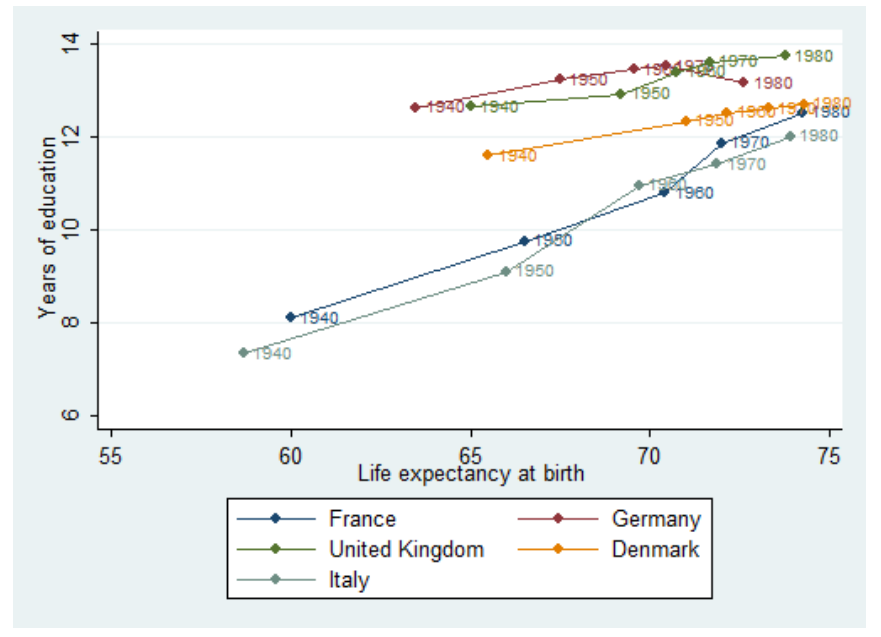

Figure 1: Years of education and period life expectancy at birth

Note that, although the Ben-Porath mechanism is a simple way to rationalize the observed patterns, alternative explanations exist. For instance, the positive correlation between education and life expectancy may result from the reverse causal chain: better education can trigger higher longevity. ${ }^{2}$ There may also be a third, omitted variable, determining jointly education and health outcomes.

But even if one abstracts from those identification problems, the observed relationship between education and longevity is far from trivial. Indeed, Figure

\footnotetext{
${ }^{1}$ Indeed, the Ben-Porath effect supposes that individuals make schooling decisions while anticipating their life horizon, which is better proxied by period life expectancy than cohort life expectancy.

${ }^{2}$ This is taken into account in models with endogenous mortality, such as Cervelatti and Sunde (2005) and de la Croix and Licandro (2012).
} 
1 displays increasing but alternatively linear, concave and convex relationships. ${ }^{3}$ All this explains why the Ben-Porath effect, although widely used by growth theorists, finds mitigated empirical support, and as such, invites some refinements on the theoretical side. ${ }^{4}$

We propose here to revisit the Ben-Porath effect, by making alternative assumptions on the education decision. Existing models presuppose that the education decision is made by a single agent (the parent or the child), whereas the family is a collective decision unit, and education is not the outcome of a single, individual decision. An abundant literature has pointed out the impact of family bargaining on various outcomes, such as time allocation and education in Konrad and Lommerud (2000), or education and fertility in de la Croix and Vander Donkt (2010). Following these works, we propose to construct a model where education results from an intrafamily bargaining, and we examine the effect of bargaining power distribution on the Ben-Porath effect.

In this paper, we develop a three-period OLG model where human capital accumulation results from an education investment decided through a bargaining process between parents and children. ${ }^{5}$ In this framework, agents educate themselves to benefit from higher wages in the future, while parents enjoy coexistence with educated children. We first characterize the optimal education from the point of view, respectively, of the child and of his parent, and, then, derive the education resulting from intrafamily bargaining. We show how the education varies with the distribution of bargaining power. Then, we analyze the long-run dynamics, when mortality is also endogenized, in order to take into account the double causal link between longevity and human capital. ${ }^{6}$

Our model shares with Cervellati and Sunde (2005) and de la Croix and Licandro (2012) the refining of the Ben-Porath mechanism by endogenizing mortality, which allows a positive feedback loop between human capital and increasing longevity. But these models are based on the simple Ben-Porath mechanism, that is to say that individuals decide alone on their own education, contrary to our model that introduces the parent's preferences in the education decision. Our model shares with Ehrlich and Lui (1991) the time-horizon effect of parents' longevity on children's education, in the context of egoistic parents' decisions for children's education. But contrary to us, Ehrlich and Lui (1991) consider that the education decision is made only by the parent. Finally, Soares (2005) takes into account both the parent's and the child's decisions with re-

\footnotetext{
${ }^{3}$ While in many models the Ben-Porath effect translates into a concave relation between education and longevity, Cohen and Soto (2004) show that mincerian returns to education imply a convex relation. The patterns in Figure 1 are neither fully concave, nor fully convex.

${ }^{4}$ See Cohen and Soto (2004, 2007), Acemoglu and Johnson (2007), Lorentzen et al (2008), and Cohen and Leker (2012) for a discussion at the empirical level.

${ }^{5}$ In our model, education is time consuming. The education investment takes the form of a fraction of time that the parent and the child must spend together. This specification is general: one can think of a father watching his child, but also of a professor teaching to a student, or of a senior worker helping a junior worker.

${ }^{6}$ For simplicity, we assume here a fixed fertility, equal to the replacement level. On the determinants of education under endogenous fertility, see Barro and Becker (1989), Erlich and Lui (1991), Soares (2005) and de la Croix and Licandro (2012).
} 
spect to human capital investment by distinguishing early education, which is within the parent's province, and high education, which is within the child's. But we differ from his approach by considering education as a collective decision, resulting from an intrafamily bargaining.

Anticipating on our results, we show that the differences in the (remaining) time horizons between the parent and the child imply a disagreement on the education investment. The child, who faces a longer time horizon, always wants, in the absence of myopia about future returns from education, more education than what his parent is willing to invest. Hence, under rational children, the higher the parent's bargaining power is, the lower the education investment is, whereas that result may be inverted when the child is myopic about future education returns. In a second stage, we study the effects of the distribution of power in the family on long-run dynamics, and show that economies with high parental bargaining power are more likely to be trapped in poverty. We also consider an extended model, where the distribution of bargaining power depends on human capital accumulation, and consider two cases: children emancipation thanks to human capital accumulation, or parental authority reinforced. We show how the relation between knowledge and power affects the long-run dynamics of the economy. Finally, we propose an empirical application of the

model on 17 OECD countries (1940-1980), and show how the introduction of family bargaining helps to rationalize the various observed patterns of education and life expectancy across countries.

The rest of the paper is organized as follows. Section 2 presents the baseline model, and studies the education decision as the outcome of an intrafamily bargaining. Section 3 examines the long-run dynamics of the economy. Section 4 endogenizes the distribution of bargaining power. Section 5 proposes an empirical illustration, and examines how the introduction of an intrafamily bargaining can help to rationalize the patterns of education and life expectancies in 17 OECD countries (1940-1980). Section 6 concludes.

\section{The basic model}

\subsection{Environment}

Let us consider a three-period OLG model. All periods are of unitary length. Each cohort is a continuum of agents, with a measure normalized to 1 . There is an implicit period of childhood not presented in the model, so that the first period is a period of young adulthood. Reproduction is monosexual, and individuals give birth to one child at the beginning of the first period.

All agents live the first period of life (young adulthood). This consists of a period during which individuals divide their time between work and education for themselves, with the help of the preceding generation. ${ }^{7}$

All agents live the second period of life (old adulthood). This is a period during which individuals work, consume, and devote time to educate their child.

\footnotetext{
${ }^{7}$ For simplicity, we assume that there is no saving decision.
} 
However, not all agents will reach the third period: only a proportion $\pi_{t+2}$ of a cohort of young adults at $t$ will enjoy the third period of life. During this third period, agents work, consume, and enjoy the companionship of their - more or less educated - children. ${ }^{8}$

The survival probability to the third period $\pi_{t+2}$ is increasing in the human capital agents enjoyed when being educated adults (second period). ${ }^{9}$ The probability of survival to the third period of life of a person who is young adult at $t$, denoted $\pi_{t+2}$, depends on the stock of human capital $h_{t+1}$ by means of the survival function:

$$
\pi_{t+2} \equiv \pi\left(h_{t+1}\right)
$$

where $\pi\left(h_{t}\right)$ exhibits the following properties: $\pi()>0,. \pi^{\prime}()>$.0 and $\pi^{\prime \prime}()<$.0 . We also assume that $\pi\left(h_{t}\right)$ is bounded from below and from above: $\lim _{h \rightarrow 0} \pi(h)=$ $\tilde{\pi}, 0<\tilde{\pi}<1$ and $\lim _{h \rightarrow \infty} \pi(h)=\bar{\pi}, 0<\tilde{\pi}<\bar{\pi}<1$.

\subsection{Production and human capital accumulation}

For simplicity, production is assumed to be linear in human capital:

$$
y_{t}=w h_{t}
$$

where $y_{t}$ denotes the output, $w$ is the wage per unit of human capital, and $h_{t}$ is the stock of human capital. For the sake of the presentation, we will normalize $w$ to 1 .

The human capital of an individual who is a young adult at time $t$ equals $h_{t}$, i.e. the human capital inherited from his parent. Then, at old adulthood, he enjoys a human capital level $h_{t+1}$, which depends on past human capital $h_{t}$, and on the time investment in education $e_{t}$. The actual returns on education investment take the following form:

$$
h_{t+1}=h\left(e_{t}\right)=A h_{t} e_{t}
$$

where $e_{t}$ is a temporal education investment, and $A$ a productivity parameter $(A>0)$.

The actual perception of the future returns from education may not be fully perfect, as some myopia may occur. To capture this, we assume that the child, when young adult, chooses his education investment on the basis of the following, perceived returns:

$$
\widetilde{h}\left(e_{t}\right)=A h_{t} e_{t}^{\rho}
$$

where $\rho$ reflects the degree of rationality of the individual when young adult $(0 \leq \rho \leq 1)$. Note that in the particular case when $\rho=1$, there is no myopia of the child. We assume, without loss of generality, that old adults, when thinking about the education of their children, perfectly anticipate the actual returns on education $h\left(e_{t+1}\right)$.

\footnotetext{
${ }^{8}$ Note that, for the sake of simplicity, we restrict ourselves here to a model with only two possible lengths of life. See Ponthiere (2011) for a study of asymptotic age structures in an OLG model with endogenous fertility.

${ }^{9}$ Many studies show that the level of human capital has an important impact on longevity, through knowledge on prevention and treatments of diseases. See Easterlin (1999).
} 


\subsection{Education decision}

Whereas existing models assume that either the child or the parent chooses the education investment, we assume in this model that both the parent and the child take part in the education decision. For simplicity, we assume that the education investment has a temporal form, and involves both the parent and the child: they must spend together a fraction of their life period to improve the child's human capital. ${ }^{10}$ The expected lifetime welfare of a young adult agent at time $t$ takes the following form:

$$
E U_{t}=\log \left(c_{t}\right)+\log \left(c_{t+1}\right)+\pi_{t+2} \log \left(c_{t+2}\right)+\pi_{t+2} \gamma \log \left(e_{t+1}\right)
$$

where $c_{t}$ is consumption at time $t, \gamma$ captures the parental taste for his child's education $(0<\gamma<1)$, and $e_{t+1}$ is the education investment of the agent's child. Note that there is no reason why the parent and the child would like to choose the same education investment, since the parental valuation of the child's education lies in the companionship with an educated child, while, for the child himself, the value of education comes from the higher wage he will get in return.

A parent young adult at $t$ and a child young adult at $t+1$ will reach an agreement on the time to devote to the child's education thanks to a bargaining at the beginning of the $t+1$ period. Hence, formally, the education investment is assumed to be the outcome of a bargaining, with a bargaining power $\varepsilon$ to the parent, and $1-\varepsilon$ to the child. Thus the education investment resulting from the bargaining is the solution of the following maximization problem:

$$
\max _{e_{t+1}} \varepsilon E U_{t}+(1-\varepsilon) E U_{t+1}
$$

where $E U_{t}$ is the expected lifetime welfare of the parent, who was a young adult at $t$, and $E U_{t+1}$ the expected lifetime welfare of the child, who will become young adult at $t+1$.

\subsubsection{The disagreement between parents and children}

Before considering the intrafamily bargaining problem, we will first explain why and to what extent the parent and the child disagree about the fraction of time to devote to education. We will therefore look at what the parent would have chosen to invest in his child's education if he was the only one to decide. Then, in a second stage, we will look at what the child would have chosen to invest in his own education if he could decide alone.

\footnotetext{
${ }^{10}$ This is equivalent to a definition of education as a monetary investment equally shared by the parent and the child.
} 
The parent's optimum The young parent at $t$ maximizes his expected utility over his child's education $e_{t+1} \cdot{ }^{11}$

$$
\begin{array}{ll}
\max _{e_{t+1}} \quad \log \left(h_{t}\left(1-e_{t}\right)\right)+\log \left(\widetilde{h}\left(e_{t}\right)\left(1-e_{t+1}\right)\right) \\
\quad+E_{t+1}\left(\pi_{t+2}\right) \log \left(\widetilde{h}\left(e_{t}\right)\right)+\gamma E_{t+1}\left(\pi_{t+2}\right) \log \left(h\left(e_{t+1}\right)\right)
\end{array}
$$

Assuming that the parent has perfect foresight, i.e. $E_{t+1}\left(\pi_{t+2}\right)=\pi_{t+2}$, the maximization of his expected utility over his child's education becomes:

$$
\begin{aligned}
\max _{e_{t+1}} & \log \left(h_{t}\left(1-e_{t}\right)\right)+\log \left(\widetilde{h}\left(e_{t}\right)\left(1-e_{t+1}\right)\right) \\
& +\pi_{t+2} \log \left(\widetilde{h}\left(e_{t}\right)\right)+\gamma \pi_{t+2} \log \left(h\left(e_{t+1}\right)\right)
\end{aligned}
$$

The first-order condition yields:

$$
\frac{h^{\prime}\left(e_{t+1}^{*}\right)}{h\left(e_{t+1}^{*}\right)}=\frac{1}{\gamma \pi_{t+2}\left(1-e_{t+1}^{*}\right)}
$$

where $e_{t+1}^{*}$ is the optimal education for the parent. As $h\left(e_{t+1}\right)=A h_{t+1} e_{t+1}$, we have:

$$
e_{t+1}^{*}=\frac{\gamma \pi_{t+2}}{1+\gamma \pi_{t+2}}
$$

Hence:

$$
\begin{aligned}
\frac{\partial e_{t+1}^{*}}{\partial \pi_{t+2}} & =\frac{\gamma}{\left(1+\gamma \pi_{t+2}\right)^{2}}>0 \\
\frac{\partial^{2} e_{t+1}^{*}}{\partial \pi_{t+2}^{2}} & =\frac{-2 \gamma^{2}}{\left(1+\gamma \pi_{t+2}\right)^{3}}<0
\end{aligned}
$$

There is a positive time horizon effect. The higher the life expectancy of the parent is, the higher the education investment in his child is ceteris paribus.

This educational investment depends also positively on the parent's taste for child's education:

$$
\frac{\partial e_{t+1}^{*}}{\partial \gamma}=\frac{\pi_{t+2}}{\left(1+\gamma \pi_{t+2}\right)^{2}}>0
$$

Moreover, as $\lim _{t \rightarrow+\infty} \pi_{t}=\bar{\pi}<1$ and as $0<\gamma<1$, we have:

$$
0<e_{t+1}^{*}<\frac{\gamma \bar{\pi}}{1+\gamma \bar{\pi}}<\frac{1}{2}
$$

The child's optimum The young adult at $t+1$ maximizes his expected utility over his own education $e_{t+1}$ :

$$
\begin{aligned}
\max _{e_{t+1}} & \log \left(h_{t+1}\left(1-e_{t+1}\right)\right)+\log \left(\widetilde{h}\left(e_{t+1}\right)\left(1-e_{t+2}\right)\right) \\
& +E_{t+1}\left(\pi_{t+3}\right) \log \left(\widetilde{h}\left(e_{t+1}\right)\right)+\gamma E_{t+1}\left(\pi_{t+3}\right) \log \left(h\left(e_{t+2}\right)\right)
\end{aligned}
$$

\footnotetext{
${ }^{11}$ We suppose that his expected utility over his child's education depends on his expected survival probability in $t+1$, since the child's education does not intervene in the first period.
} 
Assuming that the child fails to perfectly anticipate his life time horizon, i.e. $E_{t+1}\left(\pi_{t+3}\right)=\pi_{t+2}$, his problem becomes:

$$
\begin{array}{ll}
\max _{e_{t+1}} & \log \left(h_{t+1}\left(1-e_{t+1}\right)\right)+\log \left(\widetilde{h}\left(e_{t+1}\right)\left(1-e_{t+2}\right)\right) \\
& +\pi_{t+2} \log \left(\widetilde{h}\left(e_{t+1}\right)\right)+\gamma \pi_{t+2} \log \left(h\left(e_{t+2}\right)\right)
\end{array}
$$

Note that the child's expected utility differs from the parent's forwarded by one period, since the child does not perfectly anticipate his longevity. ${ }^{12}$ The FOC yields:

$$
\frac{\widetilde{h}^{\prime}\left(e_{t+1}^{* *}\right)}{\widetilde{h}\left(e_{t+1}^{* *}\right)}=\frac{1}{\left(1-e_{t+1}^{* *}\right)\left(1+\pi_{t+2}\right)}
$$

where $e_{t+1}^{* *}$ is the optimal time investment for the child in his own education. As $\widetilde{h}\left(e_{t+1}\right)=A h_{t+1} e_{t+1}^{\rho}$, we have:

$$
e_{t+1}^{* *}=\frac{\rho\left(1+\pi_{t+2}\right)}{1+\rho\left(1+\pi_{t+2}\right)}
$$

with:

$$
\begin{aligned}
\frac{\partial e_{t+1}^{* *}}{\partial \pi_{t+2}} & =\frac{\rho}{\left[1+\rho\left(1+\pi_{t+2}\right)\right]^{2}}>0 \\
\frac{\partial^{2} e_{t+1}^{* *}}{\partial \pi_{t+2}^{2}} & =-\frac{2 \rho}{\left[1+\rho\left(1+\pi_{t+2}\right)\right]^{3}}<0
\end{aligned}
$$

There is a positive time horizon effect. This is the Ben-Porath mechanism. Moreover, as $\lim _{t \rightarrow+\infty} \pi_{t}=\bar{\pi}<1$ and as $\pi()>$.0 :

$$
0<\frac{\rho}{1+\rho}<e_{t+1}^{* *}<\frac{\rho(1+\bar{\pi})}{1+\rho(1+\bar{\pi})}<\frac{2}{3}
$$

Finally,

$$
\frac{\partial e_{t+1}^{* *}}{\partial \rho}=\frac{1+\pi_{t+2}}{\left[1+\rho\left(1+\pi_{t+2}\right)\right]^{2}}>0
$$

Myopia has a negative effect on the education chosen by the child.

The disagreement between the parent and the child It follows from all this that there is no reason why the parent and the child would agree about the education investment to be engaged on the child.

If $\gamma<\rho\left[\frac{1+\pi_{t+2}}{\pi_{t+2}}\right]$, then the child wants more education than the parent. If on the contrary $\gamma>\rho\left[\frac{1+\pi}{\pi}\right]$, the child wants less education than the parent.

\footnotetext{
${ }^{12}$ Given that the parent and his child bargain and discuss about the future, it makes sense to assume that they share the same beliefs on longevity prospects. In particular, it is plausible to suppose that the parent, thanks to his older age, is better informed about the survival process (explaining that his foresight is perfect), and shares that information with his child.
} 
In the special case when there is no myopia $(\rho=1)$, the parent always wants a lower investment in his child's education than the child himself:

$$
\frac{\gamma \pi_{t+2}}{1+\gamma \pi_{t+2}}<\frac{1+\pi_{t+2}}{2+\pi_{t+2}} \Leftrightarrow e_{t+1}^{*}<e_{t+1}^{* *}
$$

The following proposition sums up our results.

Proposition 1 - The child wants more education than the parent wants for him if $\gamma<\rho\left[\frac{1+\pi_{t+2}}{\pi_{t+2}}\right]$

- The parent's and the child's optimum display a positive time horizon effect:

$$
\frac{\partial e^{*}}{\partial \pi_{t+2}}>0 \text { and } \frac{\partial e^{* *}}{\partial \pi_{t+2}}>0
$$

- As $\forall t, \tilde{\pi}<\pi_{t+2}<\bar{\pi}$ and $0<\gamma<1, e^{*}$ and $e^{* *}$ are bounded:

$$
0<e^{*}<\frac{1}{2} \text { and } 0<e^{* *}<\frac{2}{3}
$$

The parent's upper bound is lower than the child's upper bound.

Proof. See the comparison of FOCs for the child and the parent's choices of optimal $e^{*}$ and $e^{* *}$.

The origin of the disagreement between the parent and the child lies in two differences: the myopia of the child and the difference between their expected life horizons. The parent benefits from his child's education during one period only and with a probability $\pi_{t+2}$, while the child benefits from his own education potentially during two periods. Hence the disagreement comes from the failure of the child to anticipate his returns on education investment and from the heterogeneity in terms of age.

\subsubsection{Family bargaining}

The parent and the child must agree on a time period $e^{* * *}$ to devote to the child's education, since the child cannot educate himself without his parent's effort. Let us now solve the family bargaining problem, by substituting for the utility functions of the parent and the child in the bargaining function:

$$
\max _{e_{t+1}} \varepsilon E U_{t}+(1-\varepsilon) E U_{t+1}
$$

The optimal child's education is:

$$
e_{t+1}^{* * *}=\frac{\varepsilon \gamma \pi_{t+2}+\rho(1-\varepsilon)\left(1+\pi_{t+2}\right)}{1+\varepsilon \gamma \pi_{t+2}+\rho(1-\varepsilon)\left(1+\pi_{t+2}\right)}
$$

$\varepsilon$ influences negatively the child's education when the child wants more education than the parent:

$$
\frac{\partial e^{* * *}}{\partial \varepsilon}=\frac{\gamma \pi_{t+2}-\rho\left(1+\pi_{t+2}\right)}{\left[1+\varepsilon \gamma \pi_{t+2}+\rho(1-\varepsilon)\left(1+\pi_{t+2}\right)\right]^{2}} \lessgtr 0 \Longleftrightarrow \gamma \lessgtr \rho\left[\frac{1+\pi_{t+2}}{\pi_{t+2}}\right]
$$


Myopia $1-\rho$ influences negatively the child's education:

$$
\frac{\partial e^{* * *}}{\partial \rho}=\frac{(1-\varepsilon)\left(1+\pi_{t+2}\right)}{\left[1+\varepsilon \gamma \pi_{t+2}+\rho(1-\varepsilon)\left(1+\pi_{t+2}\right)\right]^{2}}>0
$$

As both the parent's and the child's optimal investment in education are subject to a time horizon effect, the fraction of time $e^{* * *}$ resulting from the bargaining is also subject to a time-horizon effect:

$$
\begin{aligned}
\frac{\partial e^{* * *}}{\partial \pi_{t+2}} & =\frac{\varepsilon \gamma+\rho(1-\varepsilon)}{\left[1+\varepsilon \gamma \pi_{t+2}+\rho(1-\varepsilon)\left(1+\pi_{t+2}\right)\right]^{2}}>0 \\
\frac{\partial^{2} e^{* * *}}{\partial \pi_{t+2}^{2}} & =-\frac{2[\varepsilon \gamma+\rho(1-\varepsilon)]^{2}}{\left[1+\varepsilon \gamma \pi_{t+2}+(1-\varepsilon)\left(1+\pi_{t+2}\right)\right]^{3}}<0
\end{aligned}
$$

The investment in human capital is increasing in the survival probability. Yet, it does not result from a pure Ben-Porath effect, nor from a pure time-horizon effect for the parent due to the companionship of his child, but from a combination of these two effects. Whether this time-horizon effect is higher or lower than the child's time horizon effect or the parent's time horizon effect remains ambiguous:

$$
\frac{\partial e^{* * * 2}}{\partial \pi_{t+2} \times \partial \varepsilon}=\frac{\begin{array}{c}
\gamma-\varepsilon \gamma^{2} \pi_{t+2}+\gamma \rho(1-\varepsilon)\left(1-\pi_{t+2}\right)-\rho \\
+\varepsilon \gamma \pi_{t+2}\left(2+\pi_{t+2}\right)+\rho^{2}(1-\varepsilon)\left(1+\pi_{t+2}\right)
\end{array}}{\left[1+\varepsilon \gamma \pi_{t+2}+(1-\varepsilon)\left(1+\pi_{t+2}\right)\right]^{3}} \gtrless 0
$$

Proposition 2 The education investment determined by the intrafamily bargaining is:

$$
e_{t+1}^{* * *}=\frac{\varepsilon \gamma \pi_{t+2}+\rho(1-\varepsilon)\left(1+\pi_{t+2}\right)}{1+\varepsilon \gamma \pi_{t+2}+\rho(1-\varepsilon)\left(1+\pi_{t+2}\right)}
$$

with:

$$
\frac{\partial e^{* * *}}{\partial \varepsilon} \gtrless 0, \frac{\partial e^{* * *}}{\partial \pi_{t+2}}>0 \text {, and } \frac{\partial e^{* * *}}{\partial \rho}>0 .
$$

Proof. See supra the FOC of the family bargaining and the derivative of the family's optimum with respect to $\pi_{t+2}$ and $\varepsilon$.

This section showed that the differences in age - and thus time horizon between the parent and the child can lead to a disagreement on the child's education, and introduced a family bargaining process to take into account both the parent's and the child's points of view. The next section explores the implications of this on long-run economic dynamics.

\section{$3 \quad$ Long-run dynamics}

Let us now characterize the long-run dynamics of the economy. Given that the survival probability $\pi_{t+1}$ and the output $y_{t}$ are functions of the human capital stock $h_{t}$, it follows that education investment $e_{t}$ is also a function of $h_{t}$. Hence 
the constancy of the human capital stock $h_{t}$ over time brings the constancy of all variables : $y_{t}, \pi_{t+1}$, and $e_{t}$.

Substituting for the level of education resulting from the family bargaining in the human capital accumulation equation yields:

$$
h_{t+1}=A\left(\frac{\varepsilon \gamma \pi\left(h_{t}\right)+\rho(1-\varepsilon)\left(1+\pi\left(h_{t}\right)\right)}{1+\gamma \varepsilon \pi\left(h_{t}\right)+\rho(1-\varepsilon)\left(1+\pi\left(h_{t}\right)\right)}\right) h_{t} \equiv G\left(h_{t}\right)
$$

The issue of the existence of a stationary equilibrium amounts to studying whether the transition function $G\left(h_{t}\right)$ admits a fixed point, that is, a value $h_{t}$ such that $G\left(h_{t}\right)=h_{t}$.

Proposition 3 The long-run dynamics of the economy belongs to one of the three following cases:

- Case 1: if $A\left(\frac{\varepsilon \gamma \tilde{\pi}+\rho(1-\varepsilon)(1+\widetilde{\pi})}{1+\varepsilon \gamma \tilde{\pi}+\rho(1-\varepsilon)(1+\widetilde{\pi})}\right)<1$ and $A\left(\frac{\varepsilon \gamma \bar{\pi}+\rho(1-\varepsilon)(1+\bar{\pi})}{1+\varepsilon \gamma \bar{\pi}+\rho(1-\varepsilon)(1+\bar{\pi})}\right)<1$, then $h^{*}=0$ is the unique stationary equilibrium: any economy with $h_{0}>0$ will converge towards $h^{*}=0$. That equilibrium is stable.

- Case 2: if $A\left(\frac{\varepsilon \gamma \tilde{\pi}+\rho(1-\varepsilon)(1+\widetilde{\pi})}{1+\varepsilon \gamma \tilde{\pi}+\rho(1-\varepsilon)(1+\widetilde{\pi})}\right)<1$ and $A\left(\frac{\varepsilon \gamma \bar{\pi}+\rho(1-\varepsilon)(1+\bar{\pi})}{1+\varepsilon \gamma \bar{\pi}+\rho(1-\varepsilon)(1+\bar{\pi})}\right)>1$, then there exists two stationary equilibria: $h^{*}=0$ and $h^{* *}>0 . h^{*}$ is locally stable, while $h^{* *}$ is unstable. Any economy with $h_{0}<h^{* *}$ will converge to $h^{*}=0$ while any economy with $h_{0}>h^{* *}$ will exhibit perpetual growth.

- Case 3: if $A\left(\frac{\varepsilon \gamma \tilde{\pi}+\rho(1-\varepsilon)(1+\tilde{\pi})}{1+\varepsilon \gamma \tilde{\pi}+\rho(1-\varepsilon)(1+\tilde{\pi})}\right)>1$ and $A\left(\frac{\varepsilon \gamma \bar{\pi}+\rho(1-\varepsilon)(1+\bar{\pi})}{1+\varepsilon \gamma \bar{\pi}+\rho(1-\varepsilon)(1+\bar{\pi})}\right)>1$, then $h^{*}=0$ is the unique stationary equilibrium. That equilibrium is unstable. Any economy with $h_{0}>0$ will exhibit perpetual growth.

Proof. See the Appendix.

Hence, depending on the productivity parameter $A$, the parameter of preference for children $\gamma$, the bounds of the survival probability $\tilde{\pi}$ and $\bar{\pi}$, the degree of the child's myopia $1-\rho$, and on the distribution of the bargaining power $\varepsilon$, an economy may experience three distinct forms of long-run dynamics, illustrated on Figure 2. ${ }^{13}$ In the first case, the economy converges towards no human capital and the lowest life expectancy $2+\tilde{\pi}$ whatever the initial human capital is. In the third case, the economy experiences perpetual growth and converges towards the highest life expectancy $2+\bar{\pi}$ whatever the initial level of human capital is. In the second case, depending on the initial human capital, the economy is either trapped in poverty or experiences perpetual growth.

\footnotetext{
${ }^{13}$ Figure 2 shows the transition function $G\left(h_{t}\right)$ and the $45^{\circ}$ line.
} 

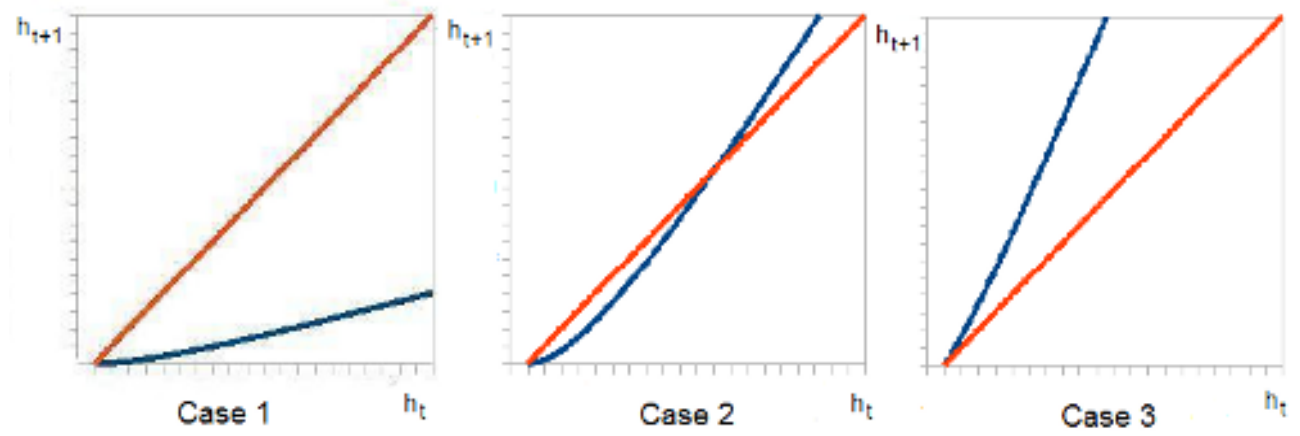

The 3 cases of long-run dynamics

The importance of the distribution of the intergenerational bargaining power regarding the likelihood of those cases is summed up in the following corollary, as well as the importance of the child's myopia $1-\rho$ :

Corollary 1 - The lower $\varepsilon$ is, the higher the likelihood of perpetual growth is, ceteris paribus.

- The higher $\gamma$ is, the higher the likelihood of perpetual growth is, $\forall \varepsilon \neq 0$, ceteris paribus.

- For the polar case $\varepsilon=1$ and $\gamma=0$, the economy is necessarily trapped in poverty.

- The higher $\rho$ is, the higher the likelihood of perpetual growth is, $\forall \varepsilon \neq 0$, ceteris paribus.

Proof. See Appendix.

Let us notice that not only $\varepsilon$, but also the productivity parameter $A$, and the limits of the survival function $\tilde{\pi}$ and $\bar{\pi}$, play a crucial role with respect to longrun dynamics. The higher $A$ is, the higher the likelihood of perpetual growth is. In particular, for $A<\frac{1+\varepsilon \gamma \bar{\pi}+\rho(1-\varepsilon)(1+\bar{\pi})}{\varepsilon \gamma \bar{\pi}+\rho(1-\varepsilon)(1+\bar{\pi})}$ perpetual growth is impossible (cases 2 or 3 are impossible). The higher $\bar{\pi}$ and $\tilde{\pi}$ are, the lower the likelihood of the existence of a poverty trap is (cases 1 or 2 ). For the polar case $\varepsilon=1$ and $\tilde{\pi}=0$, case 3 is impossible.

Proposition 3 shows that the Ben-Porath mechanism is at the very heart of the long-run dynamics of the economy. Clearly, whether the economy's dynamics falls under one case or another depends crucially on the shape of the survival function $\pi(\cdot)$, and, in particular, on its limit levels $\tilde{\pi}$ and $\bar{\pi}$.

Moreover, the introduction of a collective education investment decision refines the Ben-Porath effect by taking into account unequal time horizon effects of the parent and the child, which modifies the speed of human capital accumulation and therefore the whole transition function. The distribution of the 
bargaining power has a major influence on long-run dynamics: under rational children, the higher the parent's power is, the higher the possibility of being trapped in poverty, whereas the opposite holds under myopic children.

\section{Endogenous bargaining power}

The distribution of bargaining power within families is likely to vary over time. We examine here the robustness of our analysis to the introduction of a varying bargaining power distribution. For simplicity, we modelize $\varepsilon$ as a function of human capital:

$$
\varepsilon_{t} \equiv \varepsilon\left(h_{t}\right)
$$

That modelling is quite standard in the literature, which makes intrafamily bargaining power depend on the human capital level of individuals. ${ }^{14}$

The precise form of the functional relationship linking bargaining power to human capital can hardly be known a priori. Two opposite effects are at work. On the one hand, a child born with a higher human capital is likely to be more emancipated, thanks to his larger knowledge (prior to education). This favors a declining parental bargaining power with the human capital of the child, i.e. $\varepsilon^{\prime}\left(h_{t}\right)<0$. On the other hand, the human capital $h_{t}$ is also enjoyed by the parents, and results from their own education decision. Better educated parents can also use their knowledge to better influence their child: $\varepsilon^{\prime}\left(h_{t}\right)>0$.

Given that it is too early, at this stage, to know which effect dominates the other, we will, in the rest of this section, consider the two cases successively: firstly, the case in which $\varepsilon^{\prime}\left(h_{t}\right)<0$ (emancipation of the child thanks to a higher human capital at birth); secondly, the case in which $\varepsilon^{\prime}\left(h_{t}\right)>0$ (reinforcement of the parental authority through his own education). ${ }^{15}$

\subsection{Child's emancipation $\left(\varepsilon^{\prime}\left(h_{t}\right)<0\right)$}

In this case, when the human capital increases, the bargaining power of the child increases:

$$
\frac{\partial \varepsilon_{t}}{\partial h_{t}}<0
$$

We will use the following notations: $\lim _{h_{t} \rightarrow 0} \varepsilon\left(h_{t}\right)=\bar{\varepsilon}$ and $\lim _{h_{t} \rightarrow+\infty} \varepsilon\left(h_{t}\right)=\widetilde{\varepsilon}$. The intertemporal human capital equation now yields:

$$
h_{t+1}=A\left(\frac{\varepsilon\left(h_{t}\right) \gamma \pi\left(h_{t}\right)+\rho\left(1-\varepsilon\left(h_{t}\right)\right)\left(1+\pi\left(h_{t}\right)\right)}{1+\gamma \varepsilon\left(h_{t}\right) \pi\left(h_{t}\right)+\rho\left(1-\varepsilon\left(h_{t}\right)\right)\left(1+\pi\left(h_{t}\right)\right)}\right) h_{t} \equiv H\left(h_{t}\right)
$$

The issue of the existence of a steady-state equilibrium amounts to studying whether the transition function $H\left(h_{t}\right)$ admits a fixed point.

\footnotetext{
${ }^{14}$ See, for instance Lam and Schoeni (1993), who show that women with higher education and income have more bargaining power in their household, which implies higher schooling for their children.

${ }^{15}$ The distribution of bargaining power may also vary in a non-monotonic way. Yet, for simplicity, we will only consider a monotonic relation between the distribution of the bargaining power and human capital.
} 
Proposition 4 The long-run dynamics belongs to one of the following cases:

- Case 1: $A\left(\frac{\widetilde{\varepsilon} \gamma \tilde{\pi}+\rho(1-\widetilde{\varepsilon})(1+\widetilde{\pi})}{1+\widetilde{\varepsilon} \gamma \tilde{\pi}+\rho(1-\widetilde{\varepsilon})(1+\widetilde{\pi})}\right)<1$ and $A\left(\frac{\bar{\varepsilon} \gamma \bar{\pi}+\rho(1-\bar{\varepsilon})(1+\bar{\pi})}{1+\bar{\varepsilon} \gamma \bar{\pi}+\rho(1-\bar{\varepsilon})(1+\bar{\pi})}\right)>1$. There exist an odd number of positive stationary equilibria. There exist a poverty trap and an area of perpetual growth.

- Case 2: $A\left(\frac{\widetilde{\varepsilon} \gamma \tilde{\pi}+\rho(1-\widetilde{\varepsilon})(1+\widetilde{\pi})}{1+\tilde{\varepsilon} \gamma \tilde{\pi}+\rho(1-\widetilde{\varepsilon})(1+\widetilde{\pi})}\right)>1$ and $A\left(\frac{\bar{\varepsilon} \gamma \bar{\pi}+\rho(1-\bar{\varepsilon})(1+\bar{\pi})}{1+\bar{\varepsilon} \gamma \bar{\pi}+\rho(1-\bar{\varepsilon})(1+\bar{\pi})}\right)<1$. There exist an odd number of positive stationary equilibria. There may exist no stable equilibrium and there is no area of perpetual growth.

- Case 3: $A\left(\frac{\widetilde{\varepsilon} \gamma \tilde{\pi}+\rho(1-\widetilde{\varepsilon})(1+\widetilde{\pi})}{1+\widetilde{\varepsilon} \gamma \tilde{\pi}+\rho(1-\widetilde{\varepsilon})(1+\widetilde{\pi})}\right)<1$ and $A\left(\frac{\bar{\varepsilon} \gamma \bar{\pi}+\rho(1-\bar{\varepsilon})(1+\bar{\pi})}{1+\bar{\varepsilon} \gamma \bar{\pi}+\rho(1-\bar{\varepsilon})(1+\bar{\pi})}\right)<1$. There exist either 0 or an even number of positive stationary equilibria. There exist a poverty trap and no area of perpetual growth.

- Case 4: $A\left(\frac{\widetilde{\varepsilon} \gamma \widetilde{\pi}+\rho(1-\widetilde{\varepsilon})(1+\widetilde{\pi})}{1+\widetilde{\varepsilon} \gamma \tilde{\pi}+\rho(1-\widetilde{\varepsilon})(1+\widetilde{\pi})}\right)>1$ and $A\left(\frac{\bar{\varepsilon} \gamma \bar{\pi}+\rho(1-\bar{\varepsilon})(1+\bar{\pi})}{1+\bar{\varepsilon} \gamma \bar{\pi}+\rho(1-\bar{\varepsilon})(1+\bar{\pi})}\right)>1$. There exist either 0 or an even number of positive stationary equilibria. There may exist no stable equilibrium and there exists an area of perpetual growth.

- For every cases, if at some point $h^{* *}$ the transition function crosses the $45^{\circ}$ line from above and $\left|H^{\prime}\left(h^{* *}\right)\right|<1$, then $h^{* *}$ is a locally stable equilibrium.

Proof. See Appendix.

When the bargaining power of the parent is increasing with human capital, there may exist poverty traps, or zones of perpetual growth, but also some positive and locally stable equilibria - as the transition function $H(h)$ is non monotonous. Therefore, there may exist many pattern differences in the longrun dynamics across countries: poverty traps, perpetual growth or convergence towards different levels of output, human capital and life expectancy.

\subsection{Parental authority reinforced $\left(\varepsilon^{\prime}\left(h_{t}\right)>0\right)$}

In this case, when the human capital increases, the power of the parent increases:

$$
\frac{\partial \varepsilon_{t}}{\partial h_{t}}>0
$$

We will use the following notations: $\lim _{h_{t} \rightarrow 0} \varepsilon\left(h_{t}\right)=\widetilde{\varepsilon}$ and $\lim _{h_{t} \rightarrow+\infty} \varepsilon\left(h_{t}\right)=\bar{\varepsilon}$.

The human capital accumulation equation still yields:

$$
h_{t+1}=A\left(\frac{\varepsilon\left(h_{t}\right) \gamma \pi\left(h_{t}\right)+\rho\left(1-\varepsilon\left(h_{t}\right)\right)\left(1+\pi\left(h_{t}\right)\right)}{1+\gamma \varepsilon\left(h_{t}\right) \pi\left(h_{t}\right)+\rho\left(1-\varepsilon\left(h_{t}\right)\right)\left(1+\pi\left(h_{t}\right)\right)}\right) h_{t} \equiv J\left(h_{t}\right)
$$

The issue of the existence of a stationary equilibrium amounts to studying whether the transition function $J\left(h_{t}\right)$ admits a fixed point. 
Proposition 5 The long-run dynamics belongs to one of the following cases:

- Case 1: $A\left(\frac{\widetilde{\varepsilon} \gamma \tilde{\pi}+\rho(1-\widetilde{\varepsilon})(1+\widetilde{\pi})}{1+\widetilde{\varepsilon} \gamma \tilde{\pi}+\rho(1-\widetilde{\varepsilon})(1+\widetilde{\pi})}\right)<1$ and $A\left(\frac{\bar{\varepsilon} \gamma \bar{\pi}+\rho(1-\bar{\varepsilon})(1+\bar{\pi})}{1+\bar{\varepsilon} \gamma \bar{\pi}+\rho(1-\bar{\varepsilon})(1+\bar{\pi})}\right)>1$. There exist an odd number of positive stationary equilibria. There exist a poverty trap and an area of perpetual growth.

- Case 2: $A\left(\frac{\widetilde{\varepsilon} \gamma \tilde{\pi}+\rho(1-\widetilde{\varepsilon})(1+\widetilde{\pi})}{1+\tilde{\varepsilon} \gamma \tilde{\pi}+\rho(1-\widetilde{\varepsilon})(1+\widetilde{\pi})}\right)>1$ and $A\left(\frac{\bar{\varepsilon} \gamma \bar{\pi}+\rho(1-\bar{\varepsilon})(1+\bar{\pi})}{1+\bar{\varepsilon} \gamma \bar{\pi}+\rho(1-\bar{\varepsilon})(1+\bar{\pi})}\right)<1$ There exist an odd number of positive stationary equilibria. There may exist no stable equilibrium and there is no area of perpetual growth.

- Case 3: $A\left(\frac{\widetilde{\varepsilon} \gamma \tilde{\pi}+\rho(1-\widetilde{\varepsilon})(1+\widetilde{\pi})}{1+\widetilde{\varepsilon} \gamma \widetilde{\pi}+\rho(1-\widetilde{\varepsilon})(1+\widetilde{\pi})}\right)<1$ and $A\left(\frac{\bar{\varepsilon} \gamma \bar{\pi}+\rho(1-\bar{\varepsilon})(1+\bar{\pi})}{1+\bar{\varepsilon} \gamma \bar{\pi}+\rho(1-\bar{\varepsilon})(1+\bar{\pi})}\right)<1$. There exist either 0 or an even number of positive stationary equilibria. There exist a poverty trap and no area of perpetual growth.

- Case 4: $A\left(\frac{\widetilde{\varepsilon} \gamma \widetilde{\pi}+\rho(1-\widetilde{\varepsilon})(1+\widetilde{\pi})}{1+\widetilde{\varepsilon} \gamma \tilde{\pi}+\rho(1-\widetilde{\varepsilon})(1+\widetilde{\pi})}\right)>1$ and $A\left(\frac{\bar{\varepsilon} \gamma \bar{\pi}+\rho(1-\bar{\varepsilon})(1+\bar{\pi})}{1+\bar{\varepsilon} \gamma \bar{\pi}+\rho(1-\bar{\varepsilon})(1+\bar{\pi})}\right)>1$ There exist either 0 or an even number of positive stationary equilibria. There may exist no stable equilibrium and there exists an area of perpetual growth.

- For every cases, if at some point $h^{* *}$ the transition function crosses the $45^{\circ}$ line from above and $\left|J^{\prime}\left(h^{* *}\right)\right|<1$, then $h^{* *}$ is a locally stable equilibrium.

Proof. See Appendix.

In that case, the dynamics of the transition function are similar to the case of child's emancipation.

In sum, this section emphasized the impact of the distribution of bargaining power for long-run economic dynamics. The next section proposes to explore, by means of an empirical application, whether the introduction of family bargaining over education helps to fit the data, and evaluates the plausibility of the hypotheses of emancipation of the child and of reinforcement of parental authority with the accumulation of human capital.

\section{Empirical illustration}

In this section, we will first present some stylized facts on the evolution of education and longevity in a broad set of countries for cohorts born between 1940 and 1980, and question to what extent our model is compatible with these data. ${ }^{16}$ Then, we will propose a qualitative test of our model, which consists of checking whether the addition of intrafamily bargaining allows us to better

\footnotetext{
${ }^{16}$ For that purpose, we will set in that section $\rho=1$ to focus only on the evolution of the distribution of bargaining power in the family.
} 
explain the dynamics of life expectancy and education over time, in comparison with the simple Ben-Porath model. ${ }^{17}$

The database contains the mean year of education per cohorts born between 1940 and 1980, taken from Cohen and Leker (2012). Our database also includes period life expectancy at birth for these same cohorts taken from the World Bank for 17 OECD countries. ${ }^{18} 19$

\subsection{Stylized facts}

Our model predicts that education must be an increasing and concave function of life expectancy. Yet, as emphasized in section 1, while we observe that education increases with life expectancy, the relationships displayed by Figure 1 are more complex. Denmark displays a quasi linear relation during all the period, while the United Kingdom and France display a convex life expectancy / education relationship until 1960. The introduction of a collective decision within the family in our model helps to rationalize these relationships, as we will show below. ${ }^{20}$

To check whether our model is compatible or not with the data, we have derived values for key variables of the model, $\pi$ and $e$, from life expectancies at birth and mean years of education, considering that one period of time lasts 25 year. Table 1 displays these data for our panel of 17 OECD countries.

The simple Ben-Porath model and the data In the standard BenPorath model, the individual chooses his own education investment. This corresponds to the case in which $\varepsilon=0$ in our model, i.e. when the child has all the bargaining power. To see how this simple model fits the data or not, we compute the education investment $\hat{e}^{* *}$ predicted by the model for actual life expectancies, and try to see whether this predicted level of education coincides or not with the actual education investment. In Table 1, we observe that the predicted level of education for $\varepsilon=0, \hat{e}^{* *}$, is always higher than the actual education investment, $e$ (the mean of the difference of the two series if 0.16 with a standard deviation of 0.05). The correlation between $e$ and $\hat{e}^{* *}$ is 0.60 . The fraction of life expectancy that the individual would devote to education according to the model is much higher than what we observe in the data.

\footnotetext{
${ }^{17}$ We are aware that our model is very simple, and that our parameters may capture many other features than the bargaining power or the preference for children's education. Nonetheless, we consider this empirical section as a first way to evaluate the potential explanatory gains arising from adding intrafamily bargaining in a Ben-Porath style model.

${ }^{18}$ Australia, Austria, Belgium, Canada, Denmark, Finland, France, Germany, Ireland, Italy, Japan, Netherlands, New Zealand, Norway, Sweden, the United Kingdom and the United States.

${ }^{19}$ As the model predicts that both parents and children take their decisions while considering their expected longevity, period life expectancies are of better interest for our question than cohort life expectancies.

${ }^{20}$ There are of course other ways to rationalize such functional forms, an in particular hypotheses about the production function. See for instance Cohen and Soto (2007) on the interest of mincerian returs to education.
} 


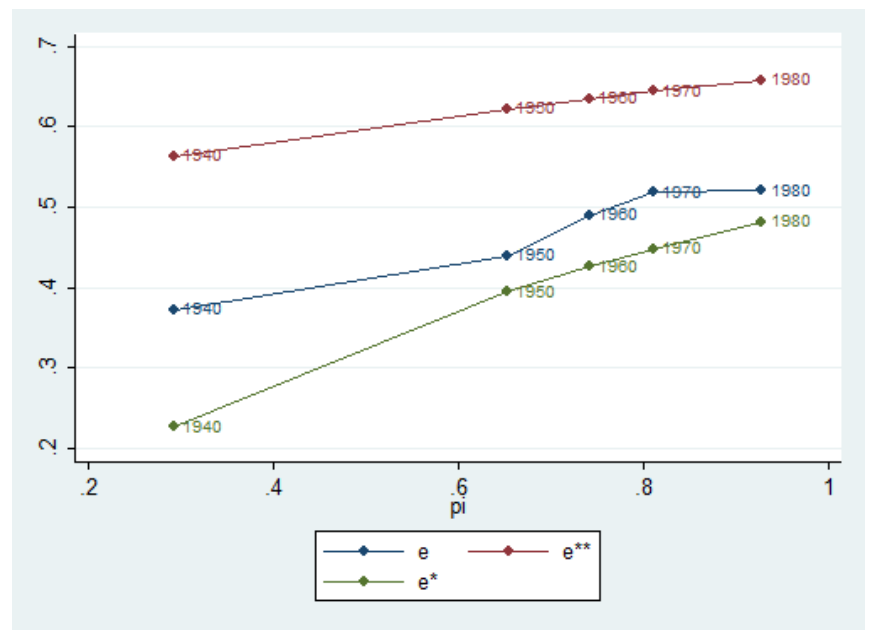

Figure 2: $e, \hat{e}^{*}$ and $\hat{e}^{* *}$ for Finland

Alternatively, if we compute the education investment predicted by the model when $\varepsilon=1, \hat{e}^{*}$, i.e. when the parent decides alone for the education of the child, even for the highest taste for his child, $\gamma=1$, the correlation between $e$ and $\hat{e}^{*}$ is 0.56. $\hat{e}^{*}$ is in most cases under $e$ (the mean of the difference of the two series is 0.05 with a standard deviation of 0.01).

Figure 2 presents $e, e^{*}$, and $e^{* *}$ for Finland for cohorts born between 1940 and 1980. The former model overestimates the education investment, while the latter model underestimates it. Neither $\hat{e}^{* *}$ nor $\hat{e}^{*}$ can fit the evolution of $e$. Hence neither a model where education is decided by the child alone, nor a model where education is decided by the parent alone, enables us to rationalize the observed data. 


\begin{tabular}{|c|c|c|c|c|c|c|c|c|c|c|c|}
\hline Country & Year & $\pi$ & $e$ & $\hat{e}^{* *}$ & $\hat{e}^{*}$ & Country & Year & $\pi$ & $e$ & $\hat{e}^{* *}$ & $\hat{e}^{*}$ \\
\hline Australia & 1940 & 0.67 & 0.46 & 0.63 & 0.40 & Finland & 1940 & 0.29 & 0.37 & 0.56 & 0.23 \\
\hline Australia & 1950 & 0.78 & 0.48 & 0.64 & 0.44 & Finland & 1950 & 0.65 & 0.44 & 0.62 & 0.39 \\
\hline Australia & 1960 & 0.83 & 0.49 & 0.65 & 0.45 & Finland & 1960 & 0.74 & 0.49 & 0.64 & 0.43 \\
\hline Australia & 1970 & 0.86 & 0.49 & 0.65 & 0.46 & Finland & 1970 & 0.81 & 0.52 & 0.64 & 0.45 \\
\hline Australia & 1980 & 0.98 & 0.51 & 0.66 & 0.49 & Finland & 1980 & 0.93 & 0.52 & 0.66 & 0.48 \\
\hline Austria & 1940 & 0.41 & 0.41 & 0.58 & 0.29 & France & 1940 & 0.40 & 0.32 & 0.58 & 0.29 \\
\hline Austria & 1950 & 0.63 & 0.45 & 0.62 & 0.39 & France & 1950 & 0.66 & 0.39 & 0.62 & 0.40 \\
\hline Austria & 1960 & 0.75 & 0.46 & 0.64 & 0.43 & France & 1960 & 0.82 & 0.43 & 0.65 & 0.45 \\
\hline Austria & 1970 & 0.81 & 0.48 & 0.64 & 0.45 & France & 1970 & 0.88 & 0.47 & 0.65 & 0.47 \\
\hline Austria & 1980 & 0.91 & 0.48 & 0.66 & 0.48 & France & 1980 & 0.97 & 0.50 & 0.66 & 0.49 \\
\hline Belgium & 1940 & 0.47 & 0.36 & 0.60 & 0.32 & Germany & 1940 & 0.54 & 0.50 & 0.61 & 0.35 \\
\hline Belgium & 1950 & 0.70 & 0.42 & 0.63 & 0.41 & Germany & 1950 & 0.70 & 0.53 & 0.63 & 0.41 \\
\hline Belgium & 1960 & 0.81 & 0.45 & 0.64 & 0.45 & Germany & 1960 & 0.78 & 0.54 & 0.64 & 0.44 \\
\hline Belgium & 1970 & 0.85 & 0.48 & 0.65 & 0.46 & Germany & 1970 & 0.82 & 0.54 & 0.65 & 0.45 \\
\hline Belgium & 1980 & 0.93 & 0.51 & 0.66 & 0.48 & Germany & 1980 & 0.91 & 0.53 & 0.66 & 0.48 \\
\hline Canada & 1940 & 0.57 & 0.49 & 0.61 & 0.36 & Ireland & 1940 & 0.39 & 0.33 & 0.58 & 0.28 \\
\hline Canada & 1950 & 0.76 & 0.51 & 0.64 & 0.43 & Ireland & 1950 & 0.68 & 0.36 & 0.63 & 0.40 \\
\hline Canada & 1960 & 0.84 & 0.53 & 0.65 & 0.46 & Ireland & 1960 & 0.79 & 0.41 & 0.64 & 0.44 \\
\hline Canada & 1970 & 0.90 & 0.55 & 0.66 & 0.47 & Ireland & 1970 & 0.84 & 0.43 & 0.65 & 0.46 \\
\hline Canada & 1980 & 0.99 & 0.55 & 0.67 & 0.50 & Ireland & 1980 & 0.91 & 0.46 & 0.66 & 0.48 \\
\hline Denmark & 1940 & 0.62 & 0.46 & 0.62 & 0.38 & Italy & 1940 & 0.39 & 0.29 & 0.57 & 0.26 \\
\hline Denmark & 1950 & 0.84 & 0.49 & 0.65 & 0.46 & Italy & 1950 & 0.64 & 0.36 & 0.62 & 0.39 \\
\hline Denmark & 1960 & 0.89 & 0.50 & 0.65 & 0.47 & Italy & 1960 & 0.79 & 0.44 & 0.64 & 0.44 \\
\hline Denmark & 1970 & 0.93 & 0.50 & 0.66 & 0.48 & Italy & 1970 & 0.88 & 0.46 & 0.65 & 0.47 \\
\hline Denmark & 1980 & 0.97 & 0.51 & 0.66 & 0.49 & Italy & 1980 & 0.96 & 0.48 & 0.66 & 0.49 \\
\hline
\end{tabular}




\begin{tabular}{|c|c|c|c|c|c|c|c|c|c|c|c|}
\hline Country & Year & $\pi$ & $e$ & $\hat{e}^{* *}$ & $\hat{e}^{*}$ & Country & Year & $\pi$ & e & $\hat{e}^{* *}$ & $\hat{e}^{*}$ \\
\hline Japan & 1940 & 0.00 & 0.45 & 0.50 & 0.00 & Sweden & 1940 & 0.67 & 0.40 & 0.63 & 0.40 \\
\hline Japan & 1950 & 0.56 & 0.49 & 0.61 & 0.36 & Sweden & 1950 & 0.87 & 0.45 & 0.65 & 0.47 \\
\hline Japan & 1960 & 0.71 & 0.53 & 0.63 & 0.41 & Sweden & 1960 & 0.93 & 0.49 & 0.66 & 0.48 \\
\hline Japan & 1970 & 0.88 & 0.54 & 0.65 & 0.47 & Sweden & 1970 & 0.98 & 0.50 & 0.66 & 0.49 \\
\hline Japan & 1980 & 1.00 & 0.54 & 0.67 & 0.50 & Sweden & 1980 & 1.00 & 0.50 & 0.67 & 0.50 \\
\hline Netherlands & 1940 & 0.70 & 0.41 & 0.63 & 0.41 & U.K. & 1940 & 0.60 & 0.51 & 0.62 & 0.38 \\
\hline Netherlands & 1950 & 0.88 & 0.45 & 0.65 & 0.47 & U.K. & 1950 & 0.77 & 0.52 & 0.64 & 0.43 \\
\hline Netherlands & 1960 & 0.93 & 0.47 & 0.66 & 0.48 & U.K. & 1960 & 0.83 & 0.54 & 0.65 & 0.45 \\
\hline Netherlands & 1970 & 0.94 & 0.48 & 0.66 & 0.48 & U.K. & 1970 & 0.87 & 0.54 & 0.65 & 0.46 \\
\hline Netherlands & 1980 & 1.00 & 0.49 & 0.67 & 0.50 & U.K. & 1980 & 0.95 & 0.55 & 0.66 & 0.49 \\
\hline New Zealand & 1940 & 0.71 & 0.43 & 0.63 & 0.41 & U.S.A. & 1940 & 0.55 & 0.50 & 0.61 & 0.36 \\
\hline New Zealand & 1950 & 0.78 & 0.47 & 0.64 & 0.44 & U.S.A. & 1950 & 0.76 & 0.52 & 0.64 & 0.43 \\
\hline New Zealand & 1960 & 0.84 & 0.50 & 0.65 & 0.46 & U.S.A. & 1960 & 0.79 & 0.53 & 0.64 & 0.44 \\
\hline New Zealand & 1970 & 0.86 & 0.51 & 0.65 & 0.46 & U.S.A. & 1970 & 0.83 & 0.53 & 0.65 & 0.45 \\
\hline New Zealand & 1980 & 0.93 & 0.52 & 0.66 & 0.48 & U.S.A. & 1980 & 0.95 & 0.53 & 0.66 & 0.49 \\
\hline Norway & 1940 & 0.69 & 0.46 & 0.63 & 0.41 & & & & & & \\
\hline Norway & 1950 & 0.91 & 0.49 & 0.66 & 0.48 & & & & & & \\
\hline Norway & 1960 & 0.94 & 0.51 & 0.66 & 0.48 & & & & & & \\
\hline Norway & 1970 & 0.97 & 0.52 & 0.66 & 0.49 & & & & & & \\
\hline Norway & 1980 & 1.00 & 0.53 & 0.67 & 0.50 & & & & & & \\
\hline
\end{tabular}

Introduction of $\varepsilon$ and $\gamma$ Let us now try to calibrate $\varepsilon$ and $\gamma$ for each country, in such a way as to fit the data. The introduction of 2 degrees of freedom enables us indeed to match the data in most cases. ${ }^{21}$ The following table presents pairs of parameters values: $\gamma$ is fixed, and $\varepsilon$ varies from 1940 to 1980 for each country. $\hat{\varepsilon}_{\gamma}$ corresponds to the level of $\varepsilon$ that would fit the data for the chosen level of $\gamma$, and for the actual levels of $\pi$ and $e$.

What is surprising in these figures is that we would have expected a decreasing $\varepsilon$ for most countries, and in particular for countries and periods for which we observe a convexity. Yet, it is not always what we observe. In many cases, $\hat{\varepsilon}_{\gamma}$ is increasing. In particular, for high levels of $\gamma, \hat{\varepsilon}_{\gamma}$ is not decreasing in Italy between 1940 and 1960 and for low levels of $\gamma, \hat{\varepsilon}_{\gamma}$ is not decreasing in the United Kingdom between 1940 and 1970, while the relationship between education and life expectancy in these countries displays convexity during these periods.

\footnotetext{
${ }^{21}$ In some few cases, we can not find an $\varepsilon$ under 1 that would fit the data for $\gamma=1$.
} 


\begin{tabular}{||l|c|c|c|c|c|c|c|c|c||}
\hline \hline Country & Year & $\pi$ & $e$ & $\widehat{\varepsilon}_{1}$ & $\widehat{\varepsilon}_{0.8}$ & $\widehat{\varepsilon}_{0.6}$ & $\widehat{\varepsilon}_{0.4}$ & $\widehat{\varepsilon}_{0.2}$ & $\widehat{\varepsilon}_{0}$ \\
\hline Australia & 1940 & 0.67 & 0.46 & 0.83 & 0.73 & 0.65 & 0.59 & 0.54 & 0.49 \\
Australia & 1950 & 0.78 & 0.48 & 0.87 & 0.75 & 0.66 & 0.59 & 0.54 & 0.49 \\
Australia & 1960 & 0.83 & 0.49 & 0.86 & 0.74 & 0.65 & 0.58 & 0.52 & 0.47 \\
Australia & 1970 & 0.86 & 0.49 & 0.89 & 0.76 & 0.66 & 0.59 & 0.53 & 0.48 \\
Australia & 1980 & 0.98 & 0.51 & 0.94 & 0.79 & 0.68 & 0.60 & 0.53 & 0.48 \\
\hline Austria & 1940 & 0.41 & 0.41 & 0.72 & 0.66 & 0.62 & 0.58 & 0.54 & 0.51 \\
Austria & 1950 & 0.63 & 0.45 & 0.82 & 0.73 & 0.66 & 0.60 & 0.55 & 0.50 \\
Austria & 1960 & 0.75 & 0.46 & 0.88 & 0.77 & 0.68 & 0.61 & 0.55 & 0.51 \\
Austria & 1970 & 0.81 & 0.48 & 0.88 & 0.76 & 0.67 & 0.59 & 0.54 & 0.49 \\
Austria & 1980 & 0.91 & 0.48 & 0.98 & 0.83 & 0.72 & 0.64 & 0.57 & 0.51 \\
\hline Belgium & 1940 & 0.47 & 0.36 & 0.90 & 0.83 & 0.76 & 0.70 & 0.66 & 0.61 \\
Belgium & 1950 & 0.70 & 0.42 & 0.98 & 0.86 & 0.77 & 0.69 & 0.63 & 0.58 \\
Belgium & 1960 & 0.81 & 0.45 & 0.99 & 0.85 & 0.75 & 0.67 & 0.60 & 0.55 \\
Belgium & 1970 & 0.85 & 0.48 & 0.92 & 0.78 & 0.68 & 0.61 & 0.55 & 0.50 \\
Belgium & 1980 & 0.93 & 0.51 & 0.91 & 0.77 & 0.66 & 0.58 & 0.52 & 0.47 \\
\hline Canada & 1940 & 0.57 & 0.49 & 0.61 & 0.54 & 0.49 & 0.45 & 0.42 & 0.39 \\
Canada & 1950 & 0.76 & 0.51 & 0.71 & 0.61 & 0.54 & 0.48 & 0.44 & 0.40 \\
Canada & 1960 & 0.84 & 0.53 & 0.71 & 0.61 & 0.53 & 0.47 & 0.43 & 0.39 \\
Canada & 1970 & 0.90 & 0.55 & 0.70 & 0.59 & 0.51 & 0.45 & 0.41 & 0.37 \\
Canada & 1980 & 0.99 & 0.55 & 0.79 & 0.66 & 0.56 & 0.49 & 0.44 & 0.40 \\
\hline Denmark & 1940 & 0.62 & 0.46 & 0.76 & 0.67 & 0.61 & 0.55 & 0.51 & 0.47 \\
Denmark & 1950 & 0.84 & 0.49 & 0.87 & 0.74 & 0.65 & 0.58 & 0.52 & 0.47 \\
Denmark & 1960 & 0.89 & 0.50 & 0.88 & 0.75 & 0.65 & 0.58 & 0.52 & 0.47 \\
Denmark & 1970 & 0.93 & 0.50 & 0.91 & 0.77 & 0.67 & 0.59 & 0.52 & 0.47 \\
Denmark & 1980 & 0.97 & 0.51 & 0.94 & 0.79 & 0.68 & 0.59 & 0.53 & 0.48 \\
\hline \hline
\end{tabular}




\begin{tabular}{||l|l|l|l|l|l|l|l|l|l||}
\hline \hline Country & Year & $\pi$ & $e$ & $\widehat{\varepsilon}_{1}$ & $\widehat{\varepsilon}_{0.8}$ & $\widehat{\varepsilon}_{0.6}$ & $\widehat{\varepsilon}_{0.4}$ & $\widehat{\varepsilon}_{0.2}$ & $\widehat{\varepsilon}_{0}$ \\
\hline Finland & 1940 & 0.29 & 0.37 & 0.70 & 0.66 & 0.63 & 0.59 & 0.57 & 0.54 \\
Finland & 1950 & 0.65 & 0.44 & 0.87 & 0.77 & 0.69 & 0.62 & 0.57 & 0.52 \\
Finland & 1960 & 0.74 & 0.49 & 0.78 & 0.68 & 0.60 & 0.54 & 0.49 & 0.45 \\
Finland & 1970 & 0.81 & 0.52 & 0.73 & 0.63 & 0.55 & 0.49 & 0.44 & 0.40 \\
Finland & 1980 & 0.93 & 0.52 & 0.84 & 0.71 & 0.61 & 0.54 & 0.48 & 0.44 \\
\hline France & 1940 & 0.40 & 0.32 & 0.92 & 0.85 & 0.79 & 0.74 & 0.70 & 0.66 \\
France & 1950 & 0.66 & 0.39 & n.a..$^{22}$ & 0.90 & 0.81 & 0.73 & 0.67 & 0.61 \\
France & 1960 & 0.82 & 0.43 & n.a. & 0.91 & 0.80 & 0.71 & 0.64 & 0.58 \\
France & 1970 & 0.88 & 0.47 & 0.98 & 0.83 & 0.72 & 0.64 & 0.57 & 0.52 \\
France & 1980 & 0.97 & 0.50 & 0.97 & 0.81 & 0.70 & 0.61 & 0.54 & 0.49 \\
\hline Germany & 1940 & 0.54 & 0.50 & 0.52 & 0.47 & 0.43 & 0.39 & 0.36 & 0.34 \\
Germany & 1950 & 0.70 & 0.53 & 0.58 & 0.51 & 0.45 & 0.41 & 0.37 & 0.34 \\
Germany & 1960 & 0.78 & 0.54 & 0.62 & 0.53 & 0.47 & 0.42 & 0.38 & 0.35 \\
Germany & 1970 & 0.82 & 0.54 & 0.64 & 0.55 & 0.48 & 0.43 & 0.39 & 0.35 \\
Germany & 1980 & 0.91 & 0.53 & 0.80 & 0.67 & 0.58 & 0.52 & 0.46 & 0.42 \\
\hline Ireland & 1940 & 0.39 & 0.33 & 0.90 & 0.83 & 0.78 & 0.73 & 0.68 & 0.65 \\
Ireland & 1950 & 0.68 & 0.36 & n.a. & 0.98 & 0.87 & 0.79 & 0.72 & 0.66 \\
Ireland & 1960 & 0.79 & 0.41 & n.a. & 0.95 & 0.83 & 0.75 & 0.67 & 0.61 \\
Ireland & 1970 & 0.84 & 0.43 & n.a. & 0.92 & 0.80 & 0.71 & 0.64 & 0.58 \\
Ireland & 1980 & 0.91 & 0.46 & n.a. & 0.88 & 0.77 & 0.68 & 0.60 & 0.55 \\
\hline Italy & 1940 & 0.35 & 0.29 & 0.93 & 0.87 & 0.82 & 0.77 & 0.73 & 0.69 \\
Italy & 1950 & 0.64 & 0.36 & n.a. & 0.95 & 0.85 & 0.77 & 0.71 & 0.65 \\
Italy & 1960 & 0.79 & 0.44 & n.a. & 0.87 & 0.77 & 0.68 & 0.62 & 0.56 \\
Italy & 1970 & 0.88 & 0.46 & n.a. & 0.88 & 0.77 & 0.68 & 0.61 & 0.55 \\
Italy & 1980 & 0.96 & 0.48 & n.a. & 0.87 & 0.75 & 0.66 & 0.59 & 0.53 \\
\hline \hline
\end{tabular}

\footnotetext{
${ }^{22}$ n.a. : non available. It is impossible to find an $\varepsilon$ under 1 that would fit the data for
} $\gamma=1$. 


\begin{tabular}{|c|c|c|c|c|c|c|c|c|c|}
\hline Country & Year & $\pi$ & $e$ & $\widehat{\varepsilon}_{1}$ & $\widehat{\varepsilon}_{0.8}$ & $\widehat{\varepsilon}_{0.6}$ & $\widehat{\varepsilon}_{0.4}$ & $\widehat{\varepsilon}_{0.2}$ & $\widehat{\varepsilon}_{0}$ \\
\hline Japan & 1940 & 0.00 & 0.45 & 0.18 & 0.18 & 0.18 & 0.18 & 0.18 & 0.18 \\
\hline Japan & 1950 & 0.56 & 0.49 & 0.59 & 0.53 & 0.49 & 0.45 & 0.41 & 0.38 \\
\hline Japan & 1960 & 0.771 & 0.53 & 0.57 & 0.50 & 0.44 & 0.40 & 0.36 & 0.33 \\
\hline Japan & 1970 & 0.88 & 0.54 & 0.68 & 0.58 & 0.50 & 0.45 & 0.40 & 0.36 \\
\hline Japan & 1980 & 1.00 & 0.54 & 0.81 & 0.68 & 0.58 & 0.51 & 0.45 & 0.41 \\
\hline Netherlands & 1940 & 0.70 & 0.41 & n.a. & 0.88 & 0.78 & 0.71 & 0.64 & 0.59 \\
\hline Netherlands & 1950 & 0.88 & 0.45 & n.a. & 0.91 & 0.79 & 0.70 & 0.63 & 0.57 \\
\hline Netherlands & 1960 & 0.93 & 0.47 & n.a. & 0.89 & 0.77 & 0.68 & 0.61 & 0.55 \\
\hline Netherlands & 1970 & 0.94 & 0.48 & n.a. & 0.86 & 0.74 & 0.65 & 0.58 & 0.52 \\
\hline Netherlands & 1980 & 1.00 & 0.49 & n.a. & 0.87 & 0.75 & 0.66 & 0.58 & 0.52 \\
\hline New Zealand & 1940 & 0.71 & 0.43 & 0.96 & 0.84 & 0.75 & 0.68 & 0.62 & 0.56 \\
\hline New Zealand & 1950 & 0.78 & 0.47 & 0.89 & 0.77 & 0.68 & 0.61 & 0.55 & 0.50 \\
\hline New Zealand & 1960 & 0.84 & 0.50 & 0.82 & 0.70 & 0.61 & 0.54 & 0.49 & 0.44 \\
\hline New Zealand & 1970 & 0.86 & 0.51 & 0.82 & 0.70 & 0.61 & 0.54 & 0.48 & 0.44 \\
\hline New Zealand & 1980 & 0.93 & 0.52 & 0.85 & 0.72 & 0.62 & 0.55 & 0.49 & 0.44 \\
\hline Norway & 1940 & 0.69 & 0.46 & 0.84 & 0.74 & 0.66 & 0.60 & 0.54 & 0.50 \\
\hline Norway & 1950 & 0.91 & 0.49 & 0.95 & 0.81 & 0.70 & 0.62 & 0.55 & 0.50 \\
\hline Norway & 1960 & 0.94 & 0.51 & 0.91 & 0.77 & 0.66 & 0.58 & 0.52 & 0.47 \\
\hline Norway & 1970 & 0.97 & 0.52 & 0.89 & 0.75 & 0.64 & 0.56 & 0.50 & 0.45 \\
\hline Norway & 1980 & 1.00 & 0.53 & 0.89 & 0.74 & 0.64 & 0.50 & 0.50 & 0.45 \\
\hline Sweden & 1940 & 0.67 & 0.40 & 1.00 & 0.88 & 0.78 & 0.71 & 0.65 & 0.60 \\
\hline Sweden & 1950 & 0.87 & 0.45 & n.a. & 0.88 & 0.77 & 0.68 & 0.61 & 0.55 \\
\hline Sweden & 1960 & 0.93 & 0.49 & 0.98 & 0.82 & 0.71 & 0.63 & 0.56 & 0.51 \\
\hline Sweden & 1970 & 0.98 & 0.50 & 1.00 & 0.83 & 0.72 & 0.63 & 0.56 & 0.50 \\
\hline Sweden & 1980 & 1.00 & 0.50 & n.a. & 0.84 & 0.72 & 0.63 & 0.56 & 0.50 \\
\hline
\end{tabular}

\begin{tabular}{||l|c|c|c|c|c|c|c|c|c||}
\hline \hline Country & Year & $\pi$ & $e$ & $\widehat{\varepsilon}_{1}$ & $\widehat{\varepsilon}_{0.8}$ & $\widehat{\widehat{\varepsilon}}_{0.6}$ & $\widehat{\widehat{\varepsilon}}_{0.4}$ & $\widehat{\varepsilon}_{0.2}$ & $\widehat{\varepsilon}_{0}$ \\
\hline U.K. & 1940 & 0.60 & 0.51 & 0.58 & 0.51 & 0.46 & 0.42 & 0.39 & 0.36 \\
U.K. & 1950 & 0.77 & 0.52 & 0.70 & 0.61 & 0.54 & 0.48 & 0.43 & 0.40 \\
U.K. & 1960 & 0.83 & 0.54 & 0.68 & 0.58 & 0.51 & 0.45 & 0.41 & 0.37 \\
U.K. & 1970 & 0.87 & 0.54 & 0.67 & 0.57 & 0.50 & 0.44 & 0.40 & 0.36 \\
U.K. & 1980 & 0.95 & 0.55 & 0.73 & 0.62 & 0.53 & 0.47 & 0.42 & 0.38 \\
\hline U.S.A. & 1940 & 0.55 & 0.50 & 0.57 & 0.51 & 0.47 & 0.43 & 0.40 & 0.37 \\
U.S.A. & 1950 & 0.76 & 0.52 & 0.66 & 0.58 & 0.51 & 0.46 & 0.41 & 0.38 \\
U.S.A. & 1960 & 0.79 & 0.53 & 0.67 & 0.58 & 0.51 & 0.46 & 0.41 & 0.38 \\
U.S.A. & 1970 & 0.83 & 0.53 & 0.72 & 0.61 & 0.54 & 0.48 & 0.43 & 0.39 \\
U.S.A. & 1980 & 1.95 & 0.53 & 0.83 & 0.70 & 0.60 & 0.53 & 0.47 & 0.43 \\
\hline \hline
\end{tabular}

The following table sums up the major trends of the evolutions of our calibrated $\varepsilon$ for the different countries in the database ${ }^{23}$ :

\footnotetext{
${ }^{23}$ We have looked at the variation of $\widehat{\varepsilon_{\gamma}}$ for each value of $\gamma$ and for each country in the database and divided these countries in two groups: one for which $\widehat{\varepsilon_{\gamma}}$ is increasing or non monotonous depending on the value of $\gamma$ and one for which $\widehat{\varepsilon_{\gamma}}$ is decreasing or non monotonous
} 


\begin{tabular}{||l|l||}
\hline \hline$\widehat{\varepsilon}$ increasing or non monotonous & $\widehat{\varepsilon}$ decreasing or non monotonous \\
parental authority reinforced & children's emancipation \\
\hline Australia & Belgium \\
Austria & Finland \\
Canada & France \\
Denmark & Ireland \\
Germany & Italy \\
Japan & Netherlands \\
United Kingdom & New Zealand \\
United States & Norway \\
& Sweden \\
\hline \hline
\end{tabular}

According to this table, the revealed relation between intergenerational bargaining power and the accumulation of human capital varies across countries. In some countries, mostly Anglo-Saxon countries and Japan (left column), the parent seems to gain power with the accumulation of human capital, whereas in other countries, mostly France and Northern Europe (right column), the child seems to become more powerful when human capital accumulates.

Since our computations entail obvious identification issues, $\widehat{\varepsilon_{\gamma}}$ does not capture only the variation of the distribution of bargaining power within the family, but also omitted determinants of education. However, we have shown that neither the simple Ben-Porath model in which $\varepsilon=0$, nor the parental model with $\varepsilon=1$, can fully rationalize the observed education and life expectancy patterns, whereas our simple model, in which education is the outcome of family bargaining, with distribution of bargaining power varying when human capital accumulates, can do the job.

\section{Conclusions}

Demography and human capital accumulation are key factors for the understanding of long-run economic dynamics. According to Ben-Porath (1967), the longer the expected lifetime is, the higher the returns on education investment are. The demand for education is, ceteris paribus, increasing in life expectancy, which is thus likely to foster human capital accumulation and growth.

In this paper, we proposed to enhance the Ben-Porath model by developing a three-period OLG model with endogenous mortality, where the education investment results from a bargaining within the family. We first introduced the bargaining power as an exogenous parameter, and, then, proposed an extension where the bargaining power is a monotonic function of human capital accumulation.

The introduction of an intrafamily bargaining on education refines the timehorizon effect pointed out by Ben-Porath: both the life expectancy of parents and the life expectancy of children determine here the education level resulting

depending on the value of $\gamma$. Note that there is no country for which $\widehat{\varepsilon_{\gamma}}$ is alternatively increasing and decreasing when $\gamma$ varies. 
from the bargaining. On the contrary, in the standard Ben-Porath, the life expectancy of children is the only demographic determinant of their demand for education. The intrafamily distribution of bargaining power matters thus for human capital accumulation: if parents are more powerful ceteris paribus, the demand for education is, in the absence of children's myopia, lower, since their remaining time horizon is shorter than their children's. Thus, when the child is fully rational, the distribution of bargaining power matters for longrun dynamics: the more powerful the child is, the higher the likelihood for an economy to experience perpetual growth. On the contrary, when the child does not fully perceive the gains from education, that effect may be inverted, and a more powerful child may reduce the growth potential of the economy.

We proposed a qualitative empirical test of our model for 17 OECD countries (1940-1980). While both models where the child decides alone on his education or when the parent decides alone for his child's education are incompatible with the data - the predicted education is much too low to fit the data in the latter case, and too high in the former case -, the introduction of a collective intergenerational decision on education enables us to better replicate the observed education and life expectancy patterns.

Yet, our model is simple, and opens several directions for future research, taking into account, among other things, the choice of fertility, or the existence of intracohort heterogeneity in lifestyles. ${ }^{24}$ Those extensions of our framework would further enrich our study of the determinants of education demand. Note, however, that the heterogeneity in life horizons between parents and children would still be at work in such extended models. Hence our requalification of the Ben-Porath effect would remain relevant in those extended models.

\section{References}

Acemoglu, D., Johnson, S., 2007, "Disease and Development: the Effect of Life Expectancy on Economic Growth", Journal of Political Economy, University of Chicago Press, vol. 115(6), pages $925-985$, December.

Barro, R., Becker, G., 1989, "Fertility Choice in a Model of Economic Growth", Econometrica, Econometric Society, vol 57(2), pages 481-501, March.

Becker, G., 1964, 1994 (3rd edition), Human Capital: A Theoretical and Empirical Analysis, with Special Reference to Education, University Press of Chicago.

Ben Porath, Y., 1967, "The Production of Human Capital and the Life-cycle of Earnings", Journal of Political Economy, University of Chicago Press, vol. 75(3), pages 352-365, June.

Boucekkine, R., de la Croix, D., Licandro, O., 2002, "Vintage Human Capital, Demographic Trends and Endogenous Growth", Journal of Economic Theory, Elsevier, vol. 104(2), pages 340-375, June.

Boucekkine, R., de la Croix, D., Licandro, O., 2003, "Early Mortality Declines at the Dawn of Modern Growth", The Scandinavian Journal of Economics, Blackwell Publishing, vol. 105(3), pages 401-418, September.

\footnotetext{
${ }^{24}$ On this, see Ponthiere (2010).
} 
Cervellati, M., Sunde, U., 2005, "Human Capital Formation, Life Expectancy and the Process of Development", The American Economic Review, American Economic Association, vol. 95(5), pages 1653-1672, December.

Cervellati, M., Sunde, U., 2007, "Human Capital, Mortality and Fertility: A Unified Theory of the Economic and Demographic Transition", CEPR Discussion Papers $\mathrm{n}^{\circ} 6384$.

Cervellati, M., Sunde, U., 2008, "The Economic and Demographic Transition, Mortality, and Comparative Development", Universität St. Gallen Discussion Paper.

Cervellati, M., Sunde, U., 2011, "Life Expectancy and Economic Growth: The Role of the Demographic Transition", Journal of Economic Growth, Springer, vol. 16(2), pages 99-133, June.

Chakraborty, S., 2004, "Endogenous Lifetime and Economic Growth", Journal of Economic Theory, Elsevier, vol 116(1), pages 119-137, May.

Cohen, D., Leker, L., 2011, "Health and Education: a New Look with Other Data", unpublished.

Cohen, D., Soto, M., 2004, "Why are Poor Countries Poor?," Econometric Society 2004 Latin American Meetings 75, Econometric Society.

Cohen, D., Soto, M., 2007, "Growth and Human Capital: Good Data, Good Results", Journal of Economic Growth, Springer, vol. 12(1), pages 51-76, March.

de la Croix, D., 2008, "Adult Longevity and Economic Take-Off : from Malthus to BenPorath", CORE Discussion Papers 2008048, Université catholique de Louvain, Center for Operations Research and Econometrics (CORE).

de la Croix, D., Licandro, O., 2012, "'The Child is Father of the Man:' Implications for the Demographic Transition", Economic Journal, forthcoming.

de la Croix, D., Lindh, T., Malmberg, B., 2009, "Demographic Change and Economic Growth in Sweden: 1750-2050," Journal of Macroeconomics, Elsevier, vol. 31(1), pages 132148, March.

de la Croix, D., and Vander Donkt, M., "Would Empowering Women Initiate the Demographic Transition in Least Developed Countries?", Journal of Human Capital, University of Chicago Press, vol. 4(2), pages 85-129.

Easterlin, R. A., 1999, "How Beneficient is the Market? A Look at the Modern History of Mortality", European Review of Economic History, vol. 3(4), pages 257-94, December.

Ehrlich, I., Lui, F., 1991, "Intergenerational Trade, Longevity, and Economic Growth", Journal of Political Economy, University of Chicago Press, vol. 99(5), pages 1029-59, October.

Konrad, K. A., and Lommerud, K. E., 2000, "The Bargainging Family Revisited", Canadian Journal of Economics, Canadian Economics Association, vol. 33(2), pages 471-487, May.

Lam, D., and Schoeni, R. F., 1993, "Effects of Family Backgrounds on Earnings and Returns to Schooling: Evidence from Brazil", Journal of Political Economy, University of Chicago Press, vol. 101(4), pages 710-40, August.

Lucas, R., 1988, "On the Mechanics of Economic Development," Journal of Monetary Economics, Elsevier, vol. 22(1), pages 3-42, July.

Lorentzen, P., McMillan, J., Wacziarg, R., 2008, "Death and Development", Journal of Economic Growth, Springer, vol. 13(2), pages 81-124, June.

Ponthiere, G., 2010, "Unequal Longevities and Lifestyles Transmission", Journal of Public Economic Theory, 12 (1), pages 93-126.

Ponthiere, G., 2011, "Asymptotic Age Structures and Intergenerational Trade", Metroeconomica, Wiley Blackwell, vol. 62(1), pages 175-217, July. 
Romer, P. M., 1990, "Endogenous Technological Change", Journal of Political Economy, University of Chicago Press, vol 98(5), pages S71-102, October.

Soares, R., 2005, "Mortality Reductions, Educational Attainment and Fertility choice", The American Economic Review, American Economic Association, vol. 95(3), pages 580-601, June.

\section{Appendix}

\subsection{Proof of Proposition 3}

The transition function is:

$$
h_{t+1}=A\left(\frac{\varepsilon \gamma \pi\left(h_{t}\right)+\rho(1-\varepsilon)\left(1+\pi\left(h_{t}\right)\right)}{1+\varepsilon \gamma \pi\left(h_{t}\right)+\rho(1-\varepsilon)\left(1+\pi\left(h_{t}\right)\right)}\right) h_{t} \equiv G\left(h_{t}\right)
$$

Note first that, given $A>0$, we have $G\left(h_{t}\right)>0$. We can also see that $G(0)=0$.

Note that $\frac{G\left(h_{t}\right)}{h_{t}}$ is increasing in $h_{t}$ as it is increasing in $\pi$ and $\pi^{\prime}\left(h_{t}\right)>0$.

Moreover, we have, under $\lim _{h_{t} \rightarrow+\infty} \pi\left(h_{t}\right)=\bar{\pi}<1$ :

$$
\lim _{h_{t} \rightarrow \infty} \frac{G\left(h_{t}\right)}{h_{t}}=A\left(\frac{\varepsilon \gamma \bar{\pi}+\rho(1-\varepsilon)(1+\bar{\pi})}{1+\varepsilon \gamma \bar{\pi}+\rho(1-\varepsilon)(1+\bar{\pi})}\right) \lessgtr 1
$$

The derivative $G^{\prime}\left(h_{t}\right)$ is:

$$
\begin{aligned}
G^{\prime}\left(h_{t}\right)= & A\left(\frac{\varepsilon \gamma \pi\left(h_{t}\right)+\rho(1-\varepsilon)\left(1+\pi\left(h_{t}\right)\right)}{1+\varepsilon \gamma \pi\left(h_{t}\right)+\rho(1-\varepsilon)\left(1+\pi\left(h_{t}\right)\right)}\right) \\
& +A h_{t} \frac{\left[\varepsilon \gamma \pi^{\prime}\left(h_{t}\right)+\rho(1-\varepsilon) \pi^{\prime}\left(h_{t}\right)\right]}{\left[1+\varepsilon \gamma \pi\left(h_{t}\right)+\rho(1-\varepsilon)\left(1+\pi\left(h_{t}\right)\right)\right]^{2}}
\end{aligned}
$$

so that $G^{\prime}\left(h_{t}\right)>0$.

Note that, under $\lim _{h_{t} \rightarrow 0} \pi\left(h_{t}\right)=\tilde{\pi}>0,0<\lim _{h_{t} \rightarrow 0} \pi^{\prime}\left(h_{t}\right)<\infty$, we have:

$$
\lim _{h_{t} \rightarrow 0} G^{\prime}\left(h_{t}\right)=A\left(\frac{\varepsilon \gamma \tilde{\pi}+\rho(1-\varepsilon)(1+\tilde{\pi})}{1+\gamma \varepsilon \tilde{\pi}+\rho(1-\varepsilon)(1+\tilde{\pi})}\right) \lessgtr 1
$$

In proposition 3 , in case $1, G\left(h_{t}\right)$ is below the $45^{\circ}$ line in the neighborhood of 0 (as $G(0)=0$ and $\lim _{h_{t} \rightarrow 0} G^{\prime}\left(h_{t}\right)<1$ ), and remains below the $45^{\circ}$ line when $h_{t}$ tends to infinity (as $\lim _{h_{t} \rightarrow \infty} \frac{G\left(h_{t}\right)}{h_{t}}<1$ ). Thus, given that $G$ is continuous, $G^{\prime}\left(h_{t}\right)>0$ and that $\frac{G\left(h_{t}\right)}{h_{t}}$ is increasing in $h_{t}, G\left(h_{t}\right)$ always remain below the $45^{\circ}$ line, so that no positive steady-state exists.

In case $2, G\left(h_{t}\right)$ is also below the $45^{\circ}$ line in the neighborhood of 0 (as $G(0)=0$ and $\lim _{h_{t} \rightarrow 0} G^{\prime}\left(h_{t}\right)<1$ ), but lies above the $45^{\circ}$ line when $h_{t}$ tends to infinity (as $\lim _{h_{t} \rightarrow \infty} \frac{G\left(h_{t}\right)}{h_{t}}>1$ ). As a consequence, given the continuity of $G\left(h_{t}\right)$, it must be the case that $G\left(h_{t}\right)$ crosses the $45^{\circ}$ line at least once at a positive $h=h^{* *}$. As $\frac{G\left(h_{t}\right)}{h_{t}}$ is increasing in $h_{t}, h^{* *}$ is the unique positive steadystate equilibrium. 
In case $3, G\left(h_{t}\right)$ is above the $45^{\circ}$ line in the neighborhood of 0 (as $G(0)=0$ and $\lim _{h_{t} \rightarrow 0} G^{\prime}\left(h_{t}\right)>1$ ), and remains above the $45^{\circ}$ line when $h_{t}$ tends to infinity (as $\lim _{h_{t} \rightarrow \infty} \frac{G\left(h_{t}\right)}{h_{t}}>1$ ). Thus, given that $G$ is continuous, $G^{\prime}\left(h_{t}\right)>0$ and that $\frac{G\left(h_{t}\right)}{h_{t}}$ is increasing in $h_{t}, G\left(h_{t}\right)$ always remain above the $45^{\circ}$ line so that no positive steady-state exists: the economy exhibits eternal growth.

\subsection{Proof of Corollary 1}

Perpetual growth is possible when $A\left(\frac{\varepsilon \gamma \bar{\pi}+\rho(1-\varepsilon)(1+\bar{\pi})}{1+\varepsilon \gamma \bar{\pi}+\rho(1-\varepsilon)(1+\bar{\pi})}\right)>1$ and sure when $A\left(\frac{\varepsilon \gamma \tilde{\pi}+\rho(1-\varepsilon)(1+\widetilde{\pi})}{1+\varepsilon \gamma \tilde{\pi}+\rho(1-\varepsilon)(1+\widetilde{\pi})}\right)>1$. Let us use the following notations: $H_{1}(\varepsilon, \gamma)=$ $\frac{\varepsilon \gamma \bar{\pi}+\rho(1-\varepsilon)(1+\bar{\pi})}{1+\varepsilon \gamma \bar{\pi}+\rho(1-\varepsilon)(1+\bar{\pi})}$ and $H_{2}(\varepsilon, \gamma)=\frac{\varepsilon \gamma \tilde{\pi}+\rho(1-\varepsilon)(1+\tilde{\pi})}{1+\varepsilon \gamma \tilde{\pi}+\rho(1-\varepsilon)(1+\tilde{\pi})}$. As both $H_{1}$ and $H_{2}$ are decreasing in $\varepsilon$, the higher $\varepsilon$, the lower the probability that $A\left(\frac{\varepsilon \gamma \bar{\pi}+\rho(1-\varepsilon)(1+\bar{\pi})}{1+\varepsilon \gamma \bar{\pi}+\rho(1-\varepsilon)(1+\bar{\pi})}\right)>$ 1 and $A\left(\frac{\varepsilon \gamma \widetilde{\pi}+\rho(1-\varepsilon)(1+\widetilde{\pi})}{1+\varepsilon \gamma \widetilde{\pi}+\rho(1-\varepsilon)(1+\widetilde{\pi})}\right)>1$.

As $\frac{\partial H_{1}(\varepsilon, \gamma)}{\partial \gamma}>0$ and $\frac{\partial H_{2}(\varepsilon, \gamma)}{\partial \gamma}>0$, but also $\frac{\partial H_{1}(\varepsilon, \gamma)}{\partial \gamma \times \partial \varepsilon}>0$ and $\frac{\partial H_{2}(\varepsilon, \gamma)}{\partial \gamma \times \partial \varepsilon}>0$, an increase in $\gamma$ increases the probability of perpetual growth and the higher $\varepsilon$, the higher this effect.

For the polar case $\varepsilon=1$ and $\gamma=0, A\left(\frac{\varepsilon \gamma \bar{\pi}+\rho(1-\varepsilon)(1+\bar{\pi})}{1+\varepsilon \gamma \bar{\pi}+\rho(1-\varepsilon)(1+\bar{\pi})}\right)=0$ and $A\left(\frac{\varepsilon \gamma \widetilde{\pi}+\rho(1-\varepsilon)(1+\widetilde{\pi})}{1+\varepsilon \gamma \widetilde{\pi}+\rho(1-\varepsilon)(1+\widetilde{\pi})}\right)=0$. The economy is trapped in poverty.

\subsection{Proof of Proposition 4}

The transition function is:

$$
h_{t+1}=A\left(\frac{\varepsilon\left(h_{t}\right) \gamma \pi\left(h_{t}\right)+\rho\left(1-\varepsilon\left(h_{t}\right)\right)\left(1+\pi\left(h_{t}\right)\right)}{1+\varepsilon\left(h_{t}\right) \gamma \pi\left(h_{t}\right)+\rho\left(1-\varepsilon\left(h_{t}\right)\right)\left(1+\pi\left(h_{t}\right)\right)}\right) h_{t} \equiv H\left(h_{t}\right)
$$

Note first that, given $A>0$, we have $H\left(h_{t}\right)>0$. We can also see that $H(0)=0$.

The derivative of $\frac{H\left(h_{t}\right)}{h_{t}}$ is:

$$
\frac{\varepsilon^{\prime}\left(h_{t}\right)\left[\gamma \pi\left(h_{t}\right)-\rho-\rho \pi\left(h_{t}\right)\right]+\pi^{\prime}\left(h_{t}\right)\left[\varepsilon\left(h_{t}\right) \gamma+\rho-\rho \varepsilon\left(h_{t}\right)\right]}{\left[1+\varepsilon\left(h_{t}\right) \gamma \pi\left(h_{t}\right)+\rho\left(1-\varepsilon\left(h_{t}\right)\right)\left(1+\pi\left(h_{t}\right)\right)\right]^{2}} \lessgtr 0
$$

since $\varepsilon^{\prime}\left(h_{t}\right)<0$ but $\gamma \lessgtr \frac{\rho\left(1+\pi\left(h_{t}\right)\right)}{\pi\left(h_{t}\right)}$.

Moreover, we have, under $\lim _{h_{t} \rightarrow+\infty} \pi\left(h_{t}\right)=\bar{\pi}<1$ and $\lim _{h_{t} \rightarrow \infty} \varepsilon\left(h_{t}\right)=\bar{\varepsilon}$ :

$$
\lim _{h_{t} \rightarrow \infty} \frac{H\left(h_{t}\right)}{h_{t}}=A\left(\frac{\bar{\varepsilon} \gamma \bar{\pi}+\rho(1-\bar{\varepsilon})(1+\bar{\pi})}{1+\bar{\varepsilon} \gamma \bar{\pi}+\rho(1-\bar{\varepsilon})(1+\bar{\pi})}\right) \lessgtr 1
$$

The derivative $H^{\prime}\left(h_{t}\right)$ is:

$$
\begin{aligned}
H^{\prime}\left(h_{t}\right)= & A\left(\frac{\varepsilon\left(h_{t}\right) \gamma \pi\left(h_{t}\right)+\rho\left(1-\varepsilon\left(h_{t}\right)\right)\left(1+\pi\left(h_{t}\right)\right)}{1+\gamma \varepsilon\left(h_{t}\right) \pi\left(h_{t}\right)+\rho\left(1-\varepsilon\left(h_{t}\right)\right)\left(1+\pi\left(h_{t}\right)\right)}\right) \\
& +A h_{t} \frac{\varepsilon^{\prime}\left(h_{t}\right)\left[\gamma \pi\left(h_{t}\right)-\rho-\rho \pi\left(h_{t}\right)\right]+\pi^{\prime}\left(h_{t}\right)\left[\varepsilon\left(h_{t}\right) \gamma+\rho-\rho \varepsilon\left(h_{t}\right)\right]}{\left[1+\gamma \varepsilon\left(h_{t}\right) \pi\left(h_{t}\right)+\rho\left(1-\varepsilon\left(h_{t}\right)\right)\left(1+\pi\left(h_{t}\right)\right)\right]^{2}}
\end{aligned}
$$


Hence $J^{\prime}\left(h_{t}\right) \lessgtr 0$, so that the transition function can cross the $45^{\circ}$ line more than once.

Note that, under $\lim _{h_{t} \rightarrow 0} \pi\left(h_{t}\right)=\tilde{\pi}>0,0<\lim _{h_{t} \rightarrow 0} \pi^{\prime}\left(h_{t}\right)<\infty$, and $\varepsilon(0)=0$, we have:

$$
\lim _{h_{t} \rightarrow 0} H^{\prime}\left(h_{t}\right)=A\left(\frac{\widetilde{\varepsilon} \gamma \tilde{\pi}+\rho(1-\widetilde{\varepsilon})(1+\tilde{\pi})}{1+\widetilde{\varepsilon} \gamma \tilde{\pi}+\rho(1-\widetilde{\varepsilon})(1+\tilde{\pi})}\right) \lessgtr 1
$$

Hence we have the following 4 cases:

In case $1, H\left(h_{t}\right)$ is below the $45^{\circ}$ line in the neighborhood of 0 (as $H(0)=0$ and $\left.\lim _{h_{t} \rightarrow 0} H^{\prime}\left(h_{t}\right)=A\left(\frac{\widetilde{\varepsilon} \gamma \widetilde{\pi}+\rho(1-\widetilde{\varepsilon})(1+\widetilde{\pi})}{1+\widetilde{\varepsilon} \gamma \widetilde{\pi}+\rho(1-\widetilde{\varepsilon})(1+\widetilde{\pi})}\right)<1\right)$, but lies above the $45^{\circ}$ line when $h_{t}$ tends to infinity (as $\lim _{h_{t} \rightarrow \infty} \frac{H\left(h_{t}\right)}{h_{t}}=A\left(\frac{\bar{\varepsilon} \gamma \bar{\pi}+\rho(1-\bar{\varepsilon})(1+\bar{\pi})}{1+\bar{\varepsilon} \gamma \bar{\pi}+\rho(1-\bar{\varepsilon})(1+\bar{\pi})}\right)>1$ ). Thus the transition function crosses the $45^{\circ}$ line at least once, but can cross it more than once since $H$ is non monotonic. Since it begins from below the $45^{\circ}$ line and ends above, it crosses the $45^{\circ}$ line an odd number of times. If $H\left(h_{t}\right)$ crosses the $45^{\circ}$ line from above at a certain point $h^{*}$, if $\left|H^{\prime}\left(h_{t}\right)\right|<1$, than $h^{*}$ is a stable equilibrium. Moreover, $H\left(h_{t}\right)$ crosses the $45^{\circ}$ line from below at least once, so that the first positive equilibrium is unstable. Hence 0 is a stable equilibrium and there exists therefore a poverty trap. Since $A\left(\frac{\bar{\varepsilon} \gamma \bar{\pi}+\rho(1-\bar{\varepsilon})(1+\bar{\pi})}{1+\bar{\varepsilon} \gamma \bar{\pi}+\rho(1-\bar{\varepsilon})(1+\bar{\pi})}\right)>1$ there exists a zone of perpetual growth.

In case $2, H\left(h_{t}\right)$ is above the $45^{\circ}$ line in the neighborhood of 0 (as $H(0)=0$ and $\left.A\left(\frac{\widetilde{\varepsilon} \gamma \widetilde{\pi}+\rho(1-\widetilde{\varepsilon})(1+\widetilde{\pi})}{1+\widetilde{\varepsilon} \gamma \widetilde{\pi}+\rho(1-\widetilde{\varepsilon})(1+\widetilde{\pi})}\right)>1\right)$, but lies below the $45^{\circ}$ line when $h_{t}$ tends to infinity $\left(\right.$ as $\left.A\left(\frac{\bar{\varepsilon} \gamma \bar{\pi}+\rho(1-\bar{\varepsilon})(1+\bar{\pi})}{1+\bar{\varepsilon} \gamma \bar{\pi}+\rho(1-\bar{\varepsilon})(1+\bar{\pi})}\right)<1\right)$. Thus the transition function crosses the $45^{\circ}$ line at least once, but can cross it more than once since $H$ is non monotonic. Since it begins from above the $45^{\circ}$ line and ends below, it crosses the $45^{\circ}$ line an odd number of times. If $H\left(h_{t}\right)$ crosses the $45^{\circ}$ line from above at a certain point $h^{*}$, if $\left|H^{\prime}\left(h_{t}\right)\right|<1$, than $h^{*}$ is a stable equilibrium. 0 is an unstable equilibrium, and there may exist no stable equilibrium. Since $A\left(\frac{\bar{\varepsilon} \gamma \bar{\pi}+\rho(1-\bar{\varepsilon})(1+\bar{\pi})}{1+\bar{\varepsilon} \gamma \bar{\pi}+\rho(1-\bar{\varepsilon})(1+\bar{\pi})}\right)<1$ there exists no zone of perpetual growth.

In case $3, H\left(h_{t}\right)$ is below the $45^{\circ}$ line in the neighborhood of 0 (as $H(0)=0$ and $\left.A\left(\frac{\widetilde{\varepsilon} \gamma \widetilde{\pi}+\rho(1-\widetilde{\varepsilon})(1+\widetilde{\pi})}{1+\widetilde{\varepsilon} \gamma \widetilde{\pi}+\rho(1-\widetilde{\varepsilon})(1+\widetilde{\pi})}\right)<1\right)$, and still lies below the $45^{\circ}$ line when $h_{t}$ tends to infinity (as $A\left(\frac{\bar{\varepsilon} \gamma \bar{\pi}+\rho(1-\bar{\varepsilon})(1+\bar{\pi})}{1+\bar{\varepsilon} \gamma \bar{\pi}+\rho(1-\bar{\varepsilon})(1+\bar{\pi})}\right)<1$ ). Thus the transition function may never cross the $45^{\circ}$ line, but can cross it an even number of times since $J$ is non monotonic. If $H\left(h_{t}\right)$ crosses the $45^{\circ}$ line from above at a certain point $h^{*}$, if $\left|H^{\prime}\left(h_{t}\right)\right|<1$, than $h^{*}$ is a stable equilibrium. Moreover, 0 is a stable equilibrium and there exists therefore a poverty trap. Since $A\left(\frac{\bar{\varepsilon} \gamma \bar{\pi}+\rho(1-\bar{\varepsilon})(1+\bar{\pi})}{1+\bar{\varepsilon} \gamma \bar{\pi}+\rho(1-\bar{\varepsilon})(1+\bar{\pi})}\right)$ there exists no zone of perpetual growth.

In case $4, H\left(h_{t}\right)$ is above the $45^{\circ}$ line in the neighborhood of 0 (as $H(0)=0$ and $\left.A\left(\frac{\widetilde{\varepsilon} \gamma \widetilde{\pi}+\rho(1-\widetilde{\varepsilon})(1+\widetilde{\pi})}{1+\widetilde{\varepsilon} \gamma \widetilde{\pi}+\rho(1-\widetilde{\varepsilon})(1+\widetilde{\pi})}\right)>1\right)$, and still lies above the $45^{\circ}$ line when $h_{t}$ tends to infinity (as $A\left(\frac{\bar{\varepsilon} \gamma \bar{\pi}+\rho(1-\bar{\varepsilon})(1+\bar{\pi})}{1+\bar{\varepsilon} \gamma \bar{\pi}+\rho(1-\bar{\varepsilon})(1+\bar{\pi})}\right)<1$ ). Thus the transition function may never cross the $45^{\circ}$ line, but can cross it an even number of times since $J$ is non 
monotonic. If $H\left(h_{t}\right)$ crosses the $45^{\circ}$ line from above at a certain point $h^{*}$, if $\left|H^{\prime}\left(h_{t}\right)\right|<1$, than $h^{*}$ is a stable equilibrium. 0 is an unstable equilibrium and there may exist no stable equilibrium. Since $A\left(\frac{\bar{\varepsilon} \gamma \bar{\pi}+\rho(1-\bar{\varepsilon})(1+\bar{\pi})}{1+\bar{\varepsilon} \gamma \bar{\pi}+\rho(1-\bar{\varepsilon})(1+\bar{\pi})}\right)>1$ there exists a zone of perpetual growth.

\subsection{Proof of Proposition 5}

The transition function is:

$$
h_{t+1}=A\left(\frac{\varepsilon\left(h_{t}\right) \gamma \pi\left(h_{t}\right)+\rho\left(1-\varepsilon\left(h_{t}\right)\right)\left(1+\pi\left(h_{t}\right)\right)}{1+\varepsilon\left(h_{t}\right) \gamma \pi\left(h_{t}\right)+\rho\left(1-\varepsilon\left(h_{t}\right)\right)\left(1+\pi\left(h_{t}\right)\right)}\right) h_{t} \equiv J\left(h_{t}\right)
$$

Note first that, given $A>0$, we have $J\left(h_{t}\right)>0$. We can also see that $J(0)=0$.

The derivative of $\frac{J\left(h_{t}\right)}{h_{t}}$ is:

$$
\frac{\varepsilon^{\prime}\left(h_{t}\right)\left[\gamma \pi\left(h_{t}\right)-\rho-\rho \pi\left(h_{t}\right)\right]+\pi^{\prime}\left(h_{t}\right)\left[\varepsilon\left(h_{t}\right) \gamma+\rho-\rho \varepsilon\left(h_{t}\right)\right]}{\left[1+\varepsilon\left(h_{t}\right) \gamma \pi\left(h_{t}\right)+\rho\left(1-\varepsilon\left(h_{t}\right)\right)\left(1+\pi\left(h_{t}\right)\right)\right]^{2}} \lessgtr 0
$$

Moreover, we have, under $\lim _{h_{t} \rightarrow+\infty} \pi\left(h_{t}\right)=\bar{\pi}<1$ and $\lim _{h_{t} \rightarrow \infty} \varepsilon\left(h_{t}\right)=\bar{\varepsilon}$ :

$$
\lim _{h_{t} \rightarrow \infty} \frac{J\left(h_{t}\right)}{h_{t}}=A\left(\frac{\bar{\varepsilon} \gamma \bar{\pi}+\rho(1-\bar{\varepsilon})(1+\bar{\pi})}{1+\bar{\varepsilon} \gamma \bar{\pi}+\rho(1-\bar{\varepsilon})(1+\bar{\pi})}\right) \lessgtr 1
$$

The derivative $J^{\prime}\left(h_{t}\right)$ is:

$$
\begin{aligned}
J^{\prime}\left(h_{t}\right)= & A\left(\frac{\varepsilon\left(h_{t}\right) \gamma \pi\left(h_{t}\right)+\rho\left(1-\varepsilon\left(h_{t}\right)\right)\left(1+\pi\left(h_{t}\right)\right)}{1+\gamma \varepsilon\left(h_{t}\right) \pi\left(h_{t}\right)+\rho\left(1-\varepsilon\left(h_{t}\right)\right)\left(1+\pi\left(h_{t}\right)\right)}\right) \\
& +A h_{t} \frac{\varepsilon^{\prime}\left(h_{t}\right)\left[\gamma \pi\left(h_{t}\right)-\rho-\rho \pi\left(h_{t}\right)\right]+\pi^{\prime}\left(h_{t}\right)\left[\varepsilon\left(h_{t}\right) \gamma+\rho-\rho \varepsilon\left(h_{t}\right)\right]}{\left[1+\gamma \varepsilon\left(h_{t}\right) \pi\left(h_{t}\right)+\rho\left(1-\varepsilon\left(h_{t}\right)\right)\left(1+\pi\left(h_{t}\right)\right)\right]^{2}}
\end{aligned}
$$

so that $J^{\prime}\left(h_{t}\right) \lessgtr 0$. Hence the transition function can cross the $45^{\circ}$ line more than once.

Note that, under $\lim _{h_{t} \rightarrow 0} \pi\left(h_{t}\right)=\widetilde{\pi}>0,0<\lim _{h_{t} \rightarrow 0} \pi^{\prime}\left(h_{t}\right)<\infty$, and $\varepsilon(0)=0$, we have:

$$
\lim _{h_{t} \rightarrow 0} J^{\prime}\left(h_{t}\right)=A\left(\frac{\widetilde{\varepsilon} \gamma \widetilde{\pi}+\rho(1-\widetilde{\varepsilon})(1+\widetilde{\pi})}{1+\widetilde{\varepsilon} \gamma \widetilde{\pi}+\rho(1-\widetilde{\varepsilon})(1+\widetilde{\pi})}\right) \lessgtr 1
$$

Hence we have the following 4 cases, similar to proposition 4 :

In case $1, J\left(h_{t}\right)$ is below the $45^{\circ}$ line in the neighborhood of 0 (as $J(0)=0$ and $\left.\lim _{h_{t} \rightarrow 0} J^{\prime}\left(h_{t}\right)=A\left(\frac{\widetilde{\varepsilon} \gamma \tilde{\pi}+\rho(1-\widetilde{\varepsilon})(1+\widetilde{\pi})}{1+\widetilde{\varepsilon} \gamma \tilde{\pi}+\rho(1-\widetilde{\varepsilon})(1+\widetilde{\pi})}\right)<1\right)$, but lies above the $45^{\circ}$ line when $h_{t}$ tends to infinity $\left(\right.$ as $\lim _{h_{t} \rightarrow \infty} \frac{J\left(h_{t}\right)}{h_{t}}=A\left(\frac{\bar{\varepsilon} \gamma \bar{\pi}+\rho(1-\bar{\varepsilon})(1+\bar{\pi})}{1+\bar{\varepsilon} \gamma \bar{\pi}+\rho(1-\bar{\varepsilon})(1+\bar{\pi})}\right)>1$ ). Thus the transition function crosses the $45^{\circ}$ line at least once, but can cross it more than once since $J$ is non monotonic. Since it begins from below the $45^{\circ}$ line and ends above, it crosses the $45^{\circ}$ line an odd number of times. If $J\left(h_{t}\right)$ crosses 
the $45^{\circ}$ line from above at a certain point $h^{*}$, if $\left|J^{\prime}\left(h_{t}\right)\right|<1$, than $h^{*}$ is a stable equilibrium. Moreover, $J\left(h_{t}\right)$ crosses the $45^{\circ}$ line from below at least once, so that the first positive equilibrium is unstable. Hence 0 is a stable equilibrium and there exists therefore a poverty trap. Since $A\left(\frac{\bar{\varepsilon} \gamma \bar{\pi}+(1-\bar{\varepsilon})(1+\bar{\pi})}{1+\bar{\varepsilon} \gamma \bar{\pi}+(1-\bar{\varepsilon})(1+\bar{\pi})}\right)>1$ there exists a zone of perpetual growth.

In case $2, J\left(h_{t}\right)$ is above the $45^{\circ}$ line in the neighborhood of 0 (as $J(0)=0$ and $\left.A\left(\frac{\widetilde{\varepsilon} \gamma \widetilde{\pi}+\rho(1-\widetilde{\varepsilon})(1+\widetilde{\pi})}{1+\widetilde{\varepsilon} \gamma \widetilde{\pi}+\rho(1-\widetilde{\varepsilon})(1+\widetilde{\pi})}\right)>1\right)$, but lies below the $45^{\circ}$ line when $h_{t}$ tends to infinity (as $\left.A\left(\frac{\bar{\varepsilon} \gamma \bar{\pi}+\rho(1-\bar{\varepsilon})(1+\bar{\pi})}{1+\bar{\varepsilon} \gamma \bar{\pi}+\rho(1-\bar{\varepsilon})(1+\bar{\pi})}\right)<1\right)$. Thus the transition function crosses the $45^{\circ}$ line at least once, but can cross it more than once since $J$ is non monotonic. Since it begins from above the $45^{\circ}$ line and ends below, it crosses the $45^{\circ}$ line an odd number of times. If $J\left(h_{t}\right)$ crosses the $45^{\circ}$ line from above at a certain point $h^{*}$, if $\left|J^{\prime}\left(h_{t}\right)\right|<1$, than $h^{*}$ is a stable equilibrium. 0 is an unstable equilibrium, and there may exist no stable equilibrium. Since $A\left(\frac{\bar{\varepsilon} \gamma \bar{\pi}+\rho(1-\bar{\varepsilon})(1+\bar{\pi})}{1+\bar{\varepsilon} \gamma \bar{\pi}+\rho(1-\bar{\varepsilon})(1+\bar{\pi})}\right)<1$ there exists no zone of perpetual growth.

In case $3, J\left(h_{t}\right)$ is below the $45^{\circ}$ line in the neighborhood of 0 (as $J(0)=0$ and $\left.A\left(\frac{\widetilde{\varepsilon} \gamma \widetilde{\pi}+\rho(1-\widetilde{\varepsilon})(1+\widetilde{\pi})}{1+\widetilde{\varepsilon} \gamma \widetilde{\pi}+\rho(1-\widetilde{\varepsilon})(1+\widetilde{\pi})}\right)<1\right)$, and still lies below the $45^{\circ}$ line when $h_{t}$ tends to infinity (as $A\left(\frac{\bar{\varepsilon} \gamma \bar{\pi}+\rho(1-\bar{\varepsilon})(1+\bar{\pi})}{1+\bar{\varepsilon} \gamma \bar{\pi}+\rho(1-\bar{\varepsilon})(1+\bar{\pi})}\right)<1$ ). Thus the transition function may never cross the $45^{\circ}$ line, but can cross it an even number of times since $J$ is non monotonic. If $J\left(h_{t}\right)$ crosses the $45^{\circ}$ line from above at a certain point $h^{*}$, if $\left|J^{\prime}\left(h_{t}\right)\right|<1$, than $h^{*}$ is a stable equilibrium. Moreover, 0 is a stable equilibrium and there exists therefore a poverty trap. Since $A\left(\frac{\bar{\varepsilon} \gamma \bar{\pi}+\rho(1-\bar{\varepsilon})(1+\bar{\pi})}{1+\bar{\varepsilon} \gamma \bar{\pi}+\rho(1-\bar{\varepsilon})(1+\bar{\pi})}\right)$ there exists no zone of perpetual growth.

In case $4, J\left(h_{t}\right)$ is above the $45^{\circ}$ line in the neighborhood of 0 (as $J(0)=0$ and $\left.A\left(\frac{\widetilde{\varepsilon} \gamma \widetilde{\pi}+\rho(1-\widetilde{\varepsilon})(1+\widetilde{\pi})}{1+\widetilde{\varepsilon} \gamma \widetilde{\pi}+\rho(1-\widetilde{\varepsilon})(1+\widetilde{\pi})}\right)>1\right)$, and still lies above the $45^{\circ}$ line when $h_{t}$ tends to infinity (as $A\left(\frac{\bar{\varepsilon} \gamma \bar{\pi}+\rho(1-\bar{\varepsilon})(1+\bar{\pi})}{1+\bar{\varepsilon} \gamma \bar{\pi}+\rho(1-\bar{\varepsilon})(1+\bar{\pi})}\right)<1$ ). Thus the transition function may never cross the $45^{\circ}$ line, but can cross it an even number of times since $J$ is non monotonic. If $J\left(h_{t}\right)$ crosses the $45^{\circ}$ line from above at a certain point $h^{*}$, if $\left|J^{\prime}\left(h_{t}\right)\right|<1$, than $h^{*}$ is a stable equilibrium. 0 is an unstable equilibrium and there may exist no stable equilibrium. Since $A\left(\frac{\bar{\varepsilon} \gamma \bar{\pi}+\rho(1-\bar{\varepsilon})(1+\bar{\pi})}{1+\bar{\varepsilon} \gamma \bar{\pi}+\rho(1-\bar{\varepsilon})(1+\bar{\pi})}\right)>1$ there exists a zone of perpetual growth. 